$$
n^{\circ} \mathbf{2 0 2 0 - 2 2}
$$

\title{
Ring the Alarm! Electricity Markets, Renewables, and the Pandemic
}

\section{David BENATIA ${ }^{1}$}




\title{
Ring the Alarm! \\ Electricity Markets, Renewables, and the Pandemic
}

\author{
David Benatia*
}

November 6, 2020

\begin{abstract}
The pandemic's impacts on European electricity markets have been enormous, especially in countries with abundant near-zero marginal cost of production like France. This article provides an in-depth quantitative study of the impacts of the crisis on the French electricity sector. During the lockdown episode, France has experienced unparalleled demand reductions $(-11.5 \%)$ and energy price falls $(-40 \%)$ resulting in revenue losses of 1.2 billion $€(-45 \%)$ for market participants. This paper argues that the observed market outcomes during the crisis are somehow indicative of outcomes in a future with abundant renewable power, where prices will fall in a more sustainable way.
\end{abstract}

Keywords: Energy Transition, COVID-19, Demand, Electricity Markets JEL Codes: L94, Q02, Q41, Q47

*CREST (UMR 9194), ENSAE, Institut Polytechnique de Paris, 5 Avenue Henry Le Chatelier, 91120 Palaiseau, France (e-mail: david.benatia@ensae.fr). This research is supported by grants of the French National Research Agency (ANR), "Investissements d'Avenir" (LabEx Ecodec/ANR-11LABX-0047) and "Instrument de financement : Projet de Recherche Collaborative - Entreprise" (ANR EcoREES). The authors acknowledge financial support from Groupe des Écoles Nationales d'Économie et Statistique (GENES) and Laboratoire de Finance des Marchés de l'Énergie (FiME). The authors would like to thank Natalia Fabra, and participants to the 7th Annual Electricity Price Forecasting and Modelling Forum, and the 30th CREEA Conference. 


\section{Introduction}

The impacts of the COVID-19 crisis on European electricity markets are reminiscent of the anticipated consequences of the ongoing energy transition. Energy efficiency improvements and increasing shares of intermittent renewables, producing at nearzero marginal costs, tend to depreciate wholesale electricity prices by reducing the market share of fossil-fuel generators. In the long-run, "too low" prices would lead to early power plant retirements and insufficient capacity investment in necessary flexible back-up technologies, which, in turn, would compromise both system reliability and efficiency. The energy transition may therefore exacerbate issues related to the "missing money problem", and more generally market incompleteness, unless markets are able to provide adequate scarcity signals.

In this paper, we argue that the sanitary crisis underlines the weaknesses of the current design of electricity markets in the face of ambitious environmental objectives. First, we develop a method to quantify the impacts of the COVID-19 crisis on interconnected electricity markets, and decompose the revenue loss for producers, retailers and grid operators with respect to their anticipation. We study different counterfactual scenarios, including one where renewable capacity is at the European Union's 2030 target. The empirical analysis focuses on the French electricity market. This market was one of the most affected in Europe due to the abundance of low-cost energy from nuclear plants combined with the drastic nationwide containment measures implemented by the government.

On March 16th 2020, French President Macron announced a nationwide lockdown as a measure to slow down the COVID-19 epidemic in France. This lockdown remained in force until May 11th. Around the same period, almost all European countries have enacted similar containment measures. Those measures have had important impacts on European power systems. The main short-term consequences have been the significant reductions in electricity consumption. CRE (2020a) reports a 17\% reduction during the lockdown in France. Renewable and nuclear energies were the two major production sources during this episode while security of supply was ensured by the flexibility of nuclear and hydro power plants. Fossil-fuel generation was reduced by $53 \%$ (CRE, 2020a). This drop in power consumption, combined with very low commodity prices 
caused by a depressed world energy consumption, and abundant near-zero marginal cost production from renewables, has resulted in unexpectedly low spot power prices. The crisis has also modified the nuclear maintenance and refueling calendars in France. As a result, nuclear power production will be lower than anticipated until 2022. ${ }^{1}$

As part of the Clean energy for all Europeans package adopted in 2019, ${ }^{2}$ France's 2030 National Energy and Climate Plan aims for 33\% renewable energy in its total energy mix. It implies that domestic power generation from renewable sources is set to increase from $27 \%$ to $40 \%$ by 2030 . The bulk of this increase will have to come from wind and solar power given the limited potential for new hydro power plants. At the same time, the share of nuclear energy is set to decrease from $70 \%$ to $50 \%$. In Europe, the share of electricity produced by renewable energy sources is expected to increase from $25 \%$ to more than $50 \%$ by 2030. The Clean energy for all Europeans package includes directives to design future highly renewable electricity markets. ${ }^{3}$ The EU Commission essentially proposes an energy-only market design with increased crossborder trade, along with additional market-based incentives for flexibility resources (e.g. energy storage and ancillary service providers, etc.). This design may, unfortunately, fall short in providing the adequate signals to guarantee long-term reliability and efficiency (Newbery et al., 2018).

Contributions and main results. This paper has three main contributions. First, we evaluate the impacts of the pandemic on electricity demand, polluting emissions and generation by sector in France using a machine-learning approach. Second, we develop a structural econometric model to disentangle the respective short-term effects of demand reductions, and fuel price drops on wholesale prices in the day-ahead market while accounting for endogenous cross-border electricity trade. Third, the estimates are used to assess losses in revenues for suppliers, retailers and grid operators. We conclude the paper with a discussion about market design adjustments for the energy transition.

\footnotetext{
${ }^{1}$ https://www.usinenouvelle.com/article/edf-revoit-a-la-hausse-son-objectif-de-production-nucleai N982226.

${ }^{2}$ https://ec.europa.eu/energy/topics/energy-strategy/clean-energy-all-europeans_ en.

${ }^{3}$ https://ec.europa.eu/energy/topics/markets-and-consumers/market-legislation/ electricity-market-design_en?redir=1
} 
Our results show that load patterns have been significantly modified and electricity consumption has reduced by around 11.5\% on average, between March 16, 2020 and May 31, 2020. These demand reductions led to important modifications of the supply mix. Fossil-fuel generation has dropped to historically low levels. Nuclear power plants have been used, jointly with hydro plants, to balance fluctuations in demand and renewable output, thanks to their manoeuvrability. The greater share of low carbon production, together with decreased demand, have driven CO2 emissions down by $42 \%$ during this period. We also remark that load forecast errors have surged for a limited time period after the enactment of containment measures.

The combination of demand reductions, caused by the lockdown, and low commodity prices, led to a $40 \%$ reduction of average wholesale electricity prices, from $26 € /$ MWh to $15 € /$ MWh. We find that $60 \%$ of this price decrease can be attributed to low fuel prices. The aggregate impact on the day-ahead market value is found at -1.2 billion $€(-45 \%)$. The impacts of the crisis might have been larger for France than for other European countries due to the abundance of low-cost nuclear power and intermittent renewables. As evidence of this claim, we find that exports have increased by $5.5 \mathrm{TWh}$ in total during this period, despite the existence of similar containment measures in neighboring countries. However, the market impacts for other systems are not quantified. A counterfactual scenario under the 2030 renewable target of $40 \%$ is studied for France. Additional renewables would have led to an extra price reduction of $-6.5 € / \mathrm{MWh}$, down to an average of $8.5 € / \mathrm{MWh}$, and nearly $50 \%$ larger market impacts.

Gross revenue losses for producers and retailers depend on each actor's respective hedging position, which are not observable. If retailers had their entire expected demand covered by futures contracts, then they have borne nearly all market losses and some suppliers have made a profit due to the crisis. Indeed hedging acts against price risk but not against volume risk which occurred with the large demand drop during the crisis. Reversely, if retailers had no hedging contracts at all, then they have "only" lost about 135 millions $€$ while suppliers have borne the remaining billion $€-$ with the largest impact for the nuclear sector. In addition, we find that the distribution grid operator has lost 100 millions $€$ in net revenues. The losses for the transmission grid operator are expected to be of similar magnitude. 
Finally, we claim that observed prices and market shares by generation sector during the lockdown are indicative of future market outcomes with abundant renewable power. Demand decreased by $11.5 \%$ and became (temporarily) more difficult to forecast, which introduced additional uncertainty around the demand net of renewable output. This context is comparable to France's 2030 renewable scenario which plans an increase of $+13 \%$ of domestic generation coming from renewable sources, assuming demand is maintained at today's pre-crisis levels. The incompleteness of current electricity markets, as discussed later on, suggests that those prices may not provide adequate signals about the needs for dispatchable capacity in the future.

Literature. This paper is related to several strands of the literature. First, it contributes to quantify the pandemic's consequences on energy markets. There are several papers evaluating demand reductions, forecast errors and market impacts in worldwide electricity markets, including Benatia (2020a,b), Ghiani et al. (2020), Leach, Rivers and Shaffer (2020), Narajewski and Ziel (2020), Percy and Mountain (2020), Ruan et al. (2020), Zhong et al. (2020), and all market impact analyses conducted by system operators (AESO, 2020; ERCOT, 2020; PJM, 2020; NYISO, 2020; RTE, 2020). Gillingham et al. (2020) discuss how the crisis may have detrimental long-run consequences for clean energy innovation, in particular by postponing renewable capacity investments. Wigand et al. (2020) show short-term evidence of such delays caused by disruptions in global supply chains, and document a significant decrease in renewable tender auction prices. At the macroeconomic level, Cicala (2020) makes use of measured demand reductions from European electricity systems to quantify the economic consequences of the crisis. We contribute to this literature by providing an in-depth analysis of the pandemic consequences on France's electricity system, which was one of the main epicenters in Europe.

Second, our empirical framework is based on a machine learning approach to estimate counterfactual outcomes in a micro-economic context. This approach builds upon ideas from Burlig et al. (2019). Related approaches are used, among others, in Benatia (2020b), Benatia and Billette de Villemeur (2019), and Graf, Quaglia and Wolak (2020). The latter argues, somehow similarly to the present paper, that realized demand reductions provide insights about the performance of future electricity 
markets with high penetration of renewables. Using a deep learning approach, they find substantial wholesale price decrease (-45\%) in Italy and document an increase of re-dispatch costs. They conclude that the costs of maintaining grid reliability may increase with the share of intermittent renewables. The advantage of using machine learning approach in our context is to obtain precise counterfactual predictions at the hourly level.

Third, our econometric model is based on economic theory. The approach of Wolfram (1999) is used to develop the functional form of the aggregate supply function. In addition, we endogenize cross-border exchanges by estimating the net import supply functions using an approach similar to Bushnell, Mansur and Saravia (2008), Brown and Olmstead (2017) and Mansur (2007). We provide justification for a different set of instrument variables than used in the above-mentioned papers: renewable power production.

Finally, there is a burgeoning literature on electricity market design for highlyrenewable markets. We summarize the most important results here, and discuss their implications in light of our analysis in the discussion section.

Electricity markets are subject to multiple market failures. The environmental externality and generators' market power are well-known failures (Fischer and Newell, 2008; Borenstein, Bushnell and Wolak, 2002). In addition, retail and wholesale prices do not fully reflect scarcity. First, retail prices are independent of hourly demand and supply variations. Ambec and Crampes (2012) use a micro-theoretic model to show that energy-only markets ${ }^{4}$ with large shares of intermittent renewables cannot decentralize the optimal energy mix in absence of price-elastic consumers. Second, wholesale prices are state-contingent but still imperfect scarcity signals. The advocates of the energy-only market design argue that market price caps, used to mitigate abuse of market power, preclude firms to collect scarcity rents to recoup their investment costs, and lead to under-investment in new capacity (Hogan, 2005). This is known as the "missing money problem" (Joskow, 2008). However, Fabra (2018) shows that the existence of market power alone leads to under-investment, even without price caps.

\footnotetext{
${ }^{4}$ In energy-only markets, suppliers earn revenues solely by selling their energy production to the wholesale market. In alternative market designs, suppliers can obtain additional remunerations by providing additional services, such as for grid reliability (e.g. capacity availability or ancillary services), which can be market-based or sold at regulated tariffs.
} 
She considers, instead, that the root of under-investment is related to missing markets for capacity availability. Indeed, capacity availability generates a positive externality by contributing to system reliability, even when not used for production. In line with Cramton and Stoft (2006), she shows that addressing the missing money problem in the presence of market power requires the introduction of capacity payments unrelated to actual energy production.

Petitet, Finon and Janssen (2017) note that energy prices will become more volatile and uncertain as the share of intermittent renewables increases, which will exacerbate issues related under-investment, even in a perfect competition framework. They contribute to this literature by showing that capacity mechanisms are more efficient than scarcity pricing to reach similar levels of reliability, if investors are risk-averse. Relatedly, Levin and Botterud (2015) demonstrate that capacity payments or regulated scarcity tariffs, established to improve the scarcity signal of energy prices when demand exceeds supply, will be increasingly needed to safeguard supply security. However, the design of capacity payments requires careful considerations to achieve efficient and reliable systems (Byers, Levin and Botterud, 2018).

In the face of ambitious renewable objectives, there are other missing markets. Henriot and Glachant (2013) argue that the market design should reflect the changes brought by renewable energy deployment: lower predictability, increased short-time variations and greater spatial granularity. Newbery et al. (2018) consider that the associated externalities should be addressed as directly as possible: by introducing more granular prices through time and space, through locational prices and additional markets with different delivery horizons. Leslie et al. (2020) recommend similar adjustments, and argue that those would be sufficient for the energy-only market design to deliver efficient and reliable systems, assuming market power mitigation mechanisms are effective.

The remaining of the paper is organized as follows. Section 2 presents the French electricity sector and estimates the effects of lockdown on demand, forecast errors, CO2 emissions amd generation by sector. Section 3 evaluates the market impacts and different counterfactual scenarios. Section 4 discusses implications for the energy transition. Section 5 concludes the paper. 


\section{The French electricity sector and the pandemic}

\subsection{The French electricity market}

The French electricity industry is subject to market competition in the generation and retail segments since the introduction of the First and Second Energy Packages of the European Union in 1996 and 2000.

The transmission and distribution segments are regulated monopolies. Réseau de Transport d'Électricité (RTE) is the legal entity in charge of grid reliability, system operations and the transmission network. Its counterpart for the distribution network is Enedis, which is in charge of the delivery to end-users (industrial, commercial and residential consumers). Their remuneration is based on a two-part tariff paid by market participants to access grid infrastructures.

The generation segment is dominated by the historical producer, Électricité de France (EDF), which is largely owned by the French State (84\%). The company operates 90.5GW of installed capacity in France, including the entire nuclear fleet and around $75 \%$ of the total hydro capacity. It was formerly a vertically-integrated public monopoly with RTE and Enedis. As a dominant firm, EDF is regulated in two main ways. First, the company is contractually committed to carry out a "public service mission" for the French State for an unlimited period. Second, electricity retailers have a regulated access to the historical nuclear production of EDF through Accès Régulé à l'Electricité Nucléaire Historique (ARENH) in order to promote upstream and downstream competition. ARENH gives access to retailers to buy electricity generated by EDF's nuclear power plants at a regulated access tariff of $42 € / \mathrm{MWh}$ for up to a total of $100 \mathrm{TWh}$ per year. ARENH rights are attributed to retailers based on their respective customer base. The low prices caused by the lockdown in France have led some retailers to renege on their ARENH contracts, by arguing force majeure.

The rest of the generation segment is divided into two medium-sized producers: Engie (25\% of French hydro capacity and some gas turbines) and Gazel Energy (2 coal-fired power plants and some renewables), and a fringe of independent producers which operates around $5 \%$ of domestic production, mainly from renewables. Wholesale suppliers are remunerated from the wholesale market and long-term contract arrange- 
ments. ${ }^{5}$ This market is part of the European Power Exchange (EPEX). It is organized as a sequential multi-unit auction where retailers buy wholesale energy from electricity suppliers. The day-ahead (or spot) market takes place one day prior to physical production and is used to allocate resources efficiently based on demand forecasts for the following day. The real-time (or intraday) market is operated near real-time and is essentially used to balance forecast errors and other contingencies.

In 2019, $72 \%$ of domestic electricity generation came from nuclear power generators, $10 \%$ from hydro plants, $10 \%$ from other renewables (wind, solar and biomass), and only $8 \%$ from fossil fuel plants (natural gas, oil and coal). In addition, the French electricity system is interconnected with 33 European countries through 6 main interfaces (Belgium, Germany, Italy, Spain, Switzerland, and the United Kingdom). France is a net exporter of electricity. 455 TWh of electricity was consumed in the country in 2019 while 68 TWh was exported and 14.5 TWh were imported - mostly from Germany during cold winter days.

Finally, the retail segment of the industry is composed of 27 actors. Historical suppliers (Engie and EDF) were managing $75 \%$ of residential and industrial clients as of March 2020. In opposition, the market share of alternative retailers represented about $25 \%$ of residential consumption and $50 \%$ of industrial consumption (CRE, 2020b). $32 \%$ of the total power consumption is still under regulated tariffs accessible to consumers with less than $36 \mathrm{kVA}$. One third of the residential tariffs cover grid operation costs, one third is for energy production, and the rest covers taxes and subsidies to renewable energy.

\subsection{Counterfactual demand, generation and emissions}

In this section, we follow the approach laid out in Benatia (2020b) to estimate the counterfactual hourly electricity demand, emissions and generation by sector, assuming the COVID-19 crisis had not happened. These counterfactual estimates will allow us to evaluate the market impacts and revenues losses caused by the crisis.

The data used in this paper has been collected from ENTSO-E's transparency

\footnotetext{
${ }^{5}$ Note that a capacity market was introduced in 2017.
} 
platform, ${ }^{6}$ RTE's data portal, ${ }^{7}$ and weather variables have been webscrapped ${ }^{8}$ for the period 2014/01-2020/05. Table 1 shows means and standard deviations (in parentheses) for the main variables of interest: actual demand (GW), forecast errors in absolute terms (MW), day-ahead price (€/MWh), CO2 emissions (kilotons/h) and the share of renewables (\%).

Table 1: Summary statistics

\begin{tabular}{cccccc}
\hline \hline Year & Actual load & Abs. Forecast error & DA price & Emissions & Renewable \\
\hline 2014 & 52.78 & 763.7 & $N a N$ & 2.20 & $5.7 \%$ \\
& $(10.84)$ & $(631.1)$ & $(N a N)$ & $(1.27)$ & $(0.02)$ \\
2015 & 54.02 & 765.0 & 38.45 & 2.59 & $6.8 \%$ \\
& $(11.60)$ & $(677.8)$ & $(12.99)$ & $(1.58)$ & $(0.03)$ \\
2016 & 54.68 & 801.0 & 36.70 & 3.15 & $7.3 \%$ \\
& $(11.51)$ & $(665.4)$ & $(24.44)$ & $(1.68)$ & $(0.03)$ \\
2017 & 54.69 & 815.4 & 44.96 & 3.08 & $8.2 \%$ \\
& $(12.53)$ & $(710.4)$ & $(20.23)$ & $(1.87)$ & $(0.04)$ \\
2018 & 54.28 & 858.0 & 50.20 & 2.09 & $8.9 \%$ \\
& $(12.20)$ & $(727.4)$ & $(18.45)$ & $(1.42)$ & $(0.04)$ \\
2019 & 53.72 & 803.7 & 39.45 & 2.00 & $10.5 \%$ \\
& $(11.53)$ & $(681.0)$ & $(14.02)$ & $(1.32)$ & $(0.05)$ \\
2020 & 52.22 & 910.6 & 28.66 & 1.63 & $12.6 \%$ \\
& $(11.96)$ & $(940.1)$ & $(11.94)$ & $(1.03)$ & $(0.06)$ \\
\hline
\end{tabular}

Notes: This table shows means and standard deviations (in parentheses) for realized load (in $\mathrm{GW}$ ), forecast errors in absolute terms (in $\mathrm{MW}$ ), day-ahead price (in $€ / \mathrm{MWh}$ ), $\mathrm{CO} 2$ emissions (in kilotons/h) and share of renewables (wind and solar) for France. Note that price data for 2014 is missing.

Counterfactual demand, emissions and generation. Our methodology consists in training a neural network capable of predicting the hourly electricity demand under business-as-usual conditions, but without relying on recent realizations or other variables which may have been affected by the crisis. The objective is to construct a credible counterfactual demand assuming containment measures had not been implemented. It must be clear that we do not propose a forecasting model. Instead, we will

\footnotetext{
${ }^{6}$ https://transparency.entsoe.eu/dashboard/show.

${ }^{7}$ https://data.rte-france.com/.

${ }^{8}$ https://rp5.ru.
} 
make use of the discrepancies between actual realizations and counterfactual estimates to infer the causal effects of the crisis on electricity demand.

The causal interpretation of the discrepancies as corresponding to the effect of the crisis relies on two assumptions. First, demand is perfectly price-inelastic. This assumption is standard for electricity demand, and allows to use machine learning prediction techniques to predict the counterfactual demand function. Second, there is no omitted variable correlated with both the timing of the crisis and variations in electricity demand. The sanitary crisis being exogenous to the economy, this assumption should be satisfied unless important predictors, such as weather variables, are omitted from the model.

The neural network model, hereafter denoted FNet, has a set of 194 predictors, all exogenous to the crisis:

- 106 hourly weather variables: dew point temperature, humidity, pressure, precipitation, temperature, visibility, wind gusts, wind speed and wind directions, cloud heights and a categorical variable for weather conditions (e.g. freezing rain, etc.) in the 10 largest cities (near their largest airport): Bordeaux, Brest, Lille, Lyon, Marseille, Nantes, Paris, Rennes, Strasbourg, Toulouse.

- 40 daily weather variables: minimum and maximum temperature and dew point temperature in the 10 largest cities.

- 48 time variables: fixed effects for hours of the day, days of the week, months of the year, a linear time trend and bank holidays occurring between March to May. ${ }^{9}$

The algorithm is a two-layer feed-forward network with a single-hidden layer and 5 neurons. It is trained by minimizing the Mean-Squared-Errors (MSE) criterion using the Levenberg-Marquardt backpropagation algorithm in MATLAB. The training sample consists of $70 \%$ of the 52,728 observations from 2014/01/01 to 2020/02/28. The remaining observations are split into a testing (10\%) and a validation (20\%) datasets. Entire days (of 24 hourly observations) are randomly attributed to each datasets in

\footnotetext{
${ }^{9}$ Other bank holidays are dropped from the sample.
} 
order to prevent overfitting since hourly observations within a day can be very similar. The algorithm is then used to predict hourly demand from 2020/03/01 to 2020/05/31.

We use the same approach to predict counterfactual CO2 emissions and generation by sector (thermal, nuclear and hydro). The data covers a shorter period from 2018/01/01 to 2020/05/31. For this reason, we reduce the number of weather variables by including only variables for three cities: Lille, Paris and Marseille. We include two additional predictors: aggregate solar and wind power production. The network structure, the training algorithm and the sample-splitting algorithm remain unchanged. However, we extend the sample period to 2020/03/08 in order to increase the number of observations.

Predictive performance and counterfactuals. The predictive performance of our algorithm (FNet) is described in Table 2 for demand and emissions. Results for generation by sector are presented in the Appendix.

For demand, the performance of FNet fairs well with respect to that of RTE's algorithm, in terms of both mean absolute (relative) prediction errors (MAPE) and root-mean-squared prediction errors (RMSE). The algorithms are trained using observations prior to March 1st, 2020 and predicted for March, April and May 2020. During the first two weeks before the lockdown (March 16th, 2020), the algorithms perform equivalently than for the test set. For example, FNet exhibits a $1.9 \%$ and $2.6 \% \mathrm{MAPE}$, which are of similar magnitudes than the $2.4 \%$ MAPE for the test set. However, as the lockdown was enacted, the MAPE surges to $14.2 \%$ for FNet and $5 \%$ for RTE. 
Table 2: Predictive performance

\begin{tabular}{|c|c|c|c|c|c|c|}
\hline & \multicolumn{4}{|c|}{ Demand } & \multicolumn{2}{|c|}{ Emissions } \\
\hline & \multicolumn{2}{|c|}{ MAPE } & \multicolumn{2}{|c|}{ RMSE } & MAPE & RMSE \\
\hline & FNet & RTE & FNet & RTE & FNet & FNet \\
\hline Test set & $2.4 \%$ & $1.5 \%$ & 1.79 & 1.05 & $27.3 \%$ & 0.57 \\
\hline 03/02-03/08 & $1.9 \%$ & $1.3 \%$ & 1.56 & 1.02 & $13.5 \%$ & 0.40 \\
\hline $03 / 09-03 / 15$ & $2.6 \%$ & $1.5 \%$ & 1.84 & 1.06 & $16.7 \%$ & 0.46 \\
\hline $03 / 16-03 / 22$ & $14.2 \%$ & $5.0 \%$ & 7.51 & 3.60 & $38.3 \%$ & 0.62 \\
\hline $03 / 23-03 / 29$ & $17.3 \%$ & $3.1 \%$ & 9.35 & 1.96 & $118.1 \%$ & 1.65 \\
\hline $03 / 30-04 / 05$ & $12.7 \%$ & $2.0 \%$ & 7.48 & 1.53 & $125.4 \%$ & 1.23 \\
\hline 04/06-04/12 & $13.9 \%$ & $1.9 \%$ & 6.37 & 1.03 & $164.8 \%$ & 0.80 \\
\hline 04/13-04/19 & $16.8 \%$ & $2.9 \%$ & 7.21 & 1.49 & $173.3 \%$ & 0.94 \\
\hline $04 / 20-04 / 26$ & $16.2 \%$ & $1.5 \%$ & 6.95 & 0.79 & $143.9 \%$ & 0.75 \\
\hline 04/27-05/04 & $13.2 \%$ & $1.4 \%$ & 6.29 & 0.75 & $45.8 \%$ & 0.32 \\
\hline $05 / 05-05 / 10$ & $11.1 \%$ & $1.9 \%$ & 4.96 & 0.89 & $85.9 \%$ & 0.84 \\
\hline $05 / 11-05 / 18$ & $9.2 \%$ & $1.6 \%$ & 4.55 & 0.90 & $86.3 \%$ & 0.94 \\
\hline $05 / 19-05 / 24$ & $7.9 \%$ & $1.7 \%$ & 3.49 & 0.81 & $57.0 \%$ & 0.70 \\
\hline $05 / 25-05 / 31$ & $7.3 \%$ & $1.7 \%$ & 3.19 & 0.87 & $17.4 \%$ & 0.25 \\
\hline
\end{tabular}

Notes: This table shows the performance of our model (FNet) and the day-ahead forecasts used by RTE to predict hourly electricity consumption for the test set. Figure 10 in the Appendix compares actual and counterfactual demand distributions.

The prediction errors of RTE's algorithm are shown in Figure 1. Those errors reduced down to usual levels within 3 to 5 weeks, and the MAPE remained below $5 \%$, which is evidence that RTE has adapted quickly to the structural break created by containment measures. 


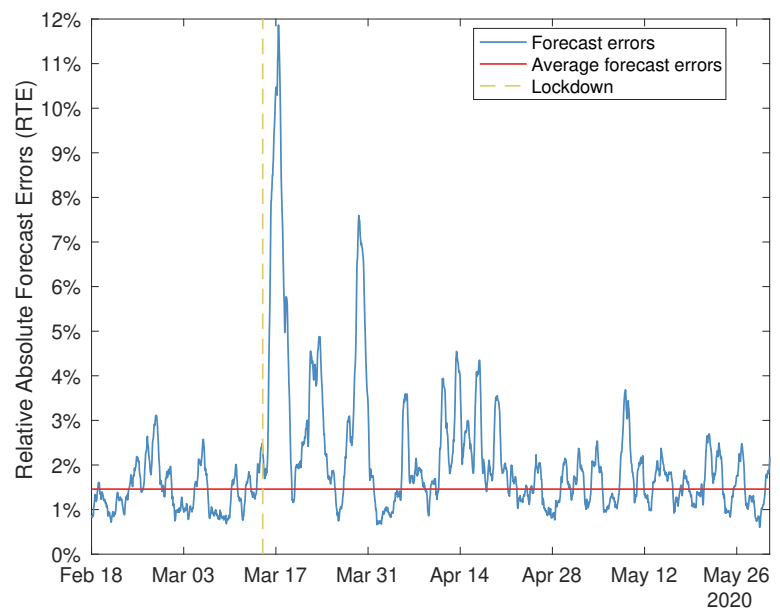

Figure 1: Relative Absolute Forecast errors (RTE)

Although forecast errors were quickly attenuated, demand remained away from its usual levels. The MAPE for FNet was larger than 5\% in March, April and May and the predicted counterfactual demand, under business-as-usual conditions, is found consistently larger than realized levels during April and May as shown in Figure 2a and 2b. Note that all Figures report moving-averages of varying orders to help readability.

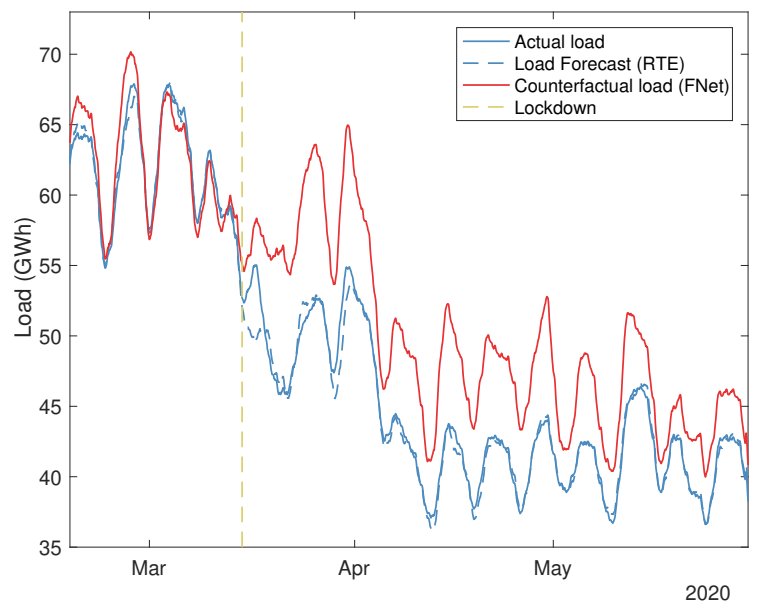

(a) $02 / 18-05 / 31$

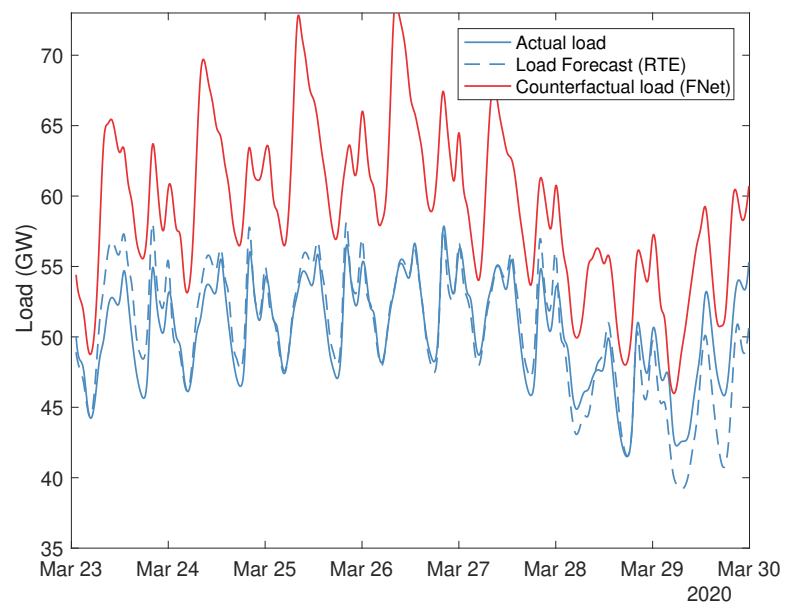

(b) $03 / 23-03 / 29$

Figure 2: Actual load and predictions

The performance of FNet to predict CO2 emissions is not as good. Nevertheless, we observe a sharp increase in MAPE from about $20 \%$ to above $150 \%$ followed by a 
gradual decrease during the period under study. Figure 3 shows the extent to which the crisis caused a reduction in $\mathrm{CO} 2$ emissions. The majority of emissions reductions seem to have occurred during the first two weeks of the lockdown.

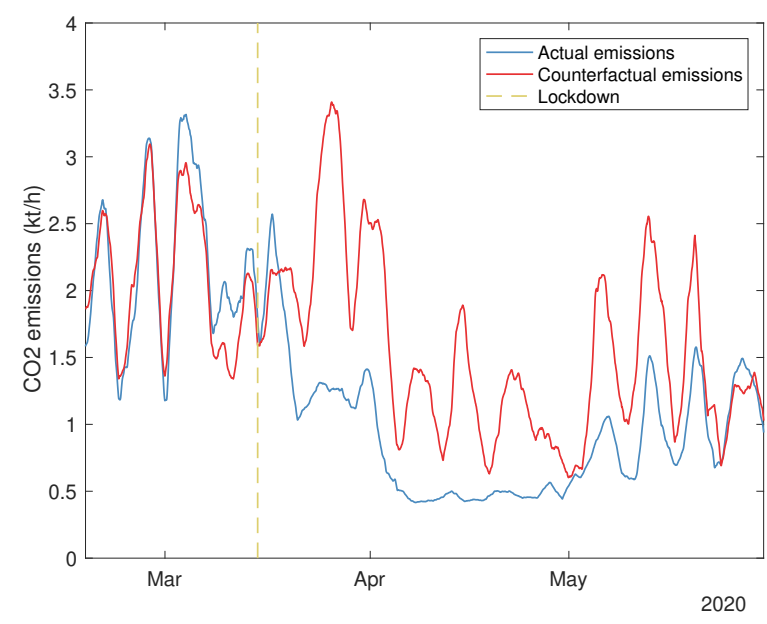

Figure 3: CO2 emissions

Finally, we report the counterfactual generations by sector in Figure 4. We find systematic downward deviations of thermal and nuclear generations after the lockdown was enacted. There is no such systematic deviations for hydropower production. Thermal production was considerably reduced from mid-March to early May. Interestingly, its level was kept nearly constant at record lows. The equilibrium between supply and demand was instead assured by the load-following capabilities of nuclear plants. Figure $4 \mathrm{~b}$ shows that the fluctuations of nuclear generation have been much larger than usual during this period. 


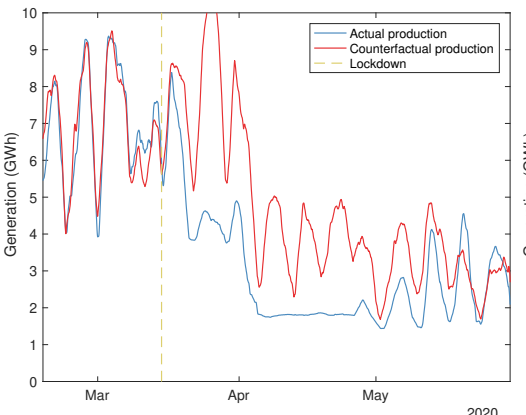

(a) Thermal generation

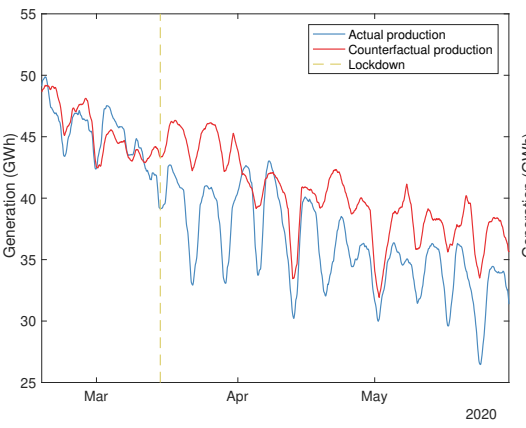

(b) Nuclear generation

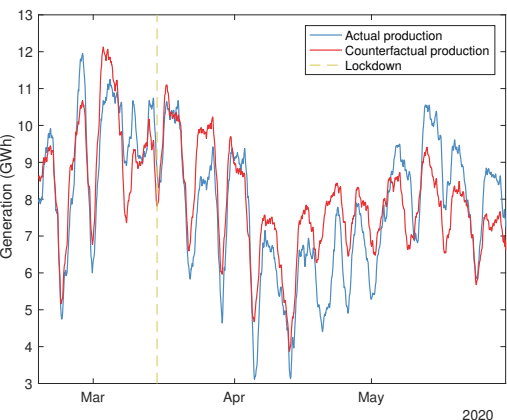

(c) Hydro generation

Figure 4: Actual and predicted generation (FNET)

Weekly demand and emissions reductions. Weekly demand and emissions reductions during the lockdown were huge. They are estimated as the aggregated differences by week between realized demand and its counterfactual had the crisis not occurred. Table 3 reports the weekly estimates and standard errors (in parentheses).

The largest reduction in electricity consumption occurred during the second week of the lockdown with -1500 GWh (15\%) of weekly demand. At the same time, emissions dropped by 245 kilotons (54\%). From March 16th to May 31st, consumption was 10 TWh smaller than usual, that is $11.5 \%$, and emissions have been $41.5 \%$ smaller. For comparison, Benatia (2020b) finds that, in the state of New York over the same period, demand had reduced by about $8 \%$. 
Table 3: Weekly demand reductions (GWh)

\begin{tabular}{lcccccc}
\hline \hline & \multicolumn{3}{c}{ Demand } & \multicolumn{3}{c}{ Emissions } \\
\hline $03 / 16-03 / 22$ & -1135.5 & $(97.0)$ & $-12.0 \%$ & -45.3 & $(30.3)$ & $-13.6 \%$ \\
$03 / 23-03 / 29$ & -1473.2 & $(97.0)$ & $-14.8 \%$ & -245.1 & $(30.3)$ & $-54.1 \%$ \\
$03 / 30-04 / 05$ & -1104.6 & $(97.0)$ & $-11.6 \%$ & -178.2 & $(30.3)$ & $-53.3 \%$ \\
$04 / 06-04 / 12$ & -972.0 & $(97.0)$ & $-12.3 \%$ & -118.4 & $(30.3)$ & $-61.7 \%$ \\
$04 / 13-04 / 19$ & -1143.6 & $(97.0)$ & $-14.3 \%$ & -128.7 & $(30.3)$ & $-62.7 \%$ \\
$04 / 20-04 / 26$ & -1107.7 & $(97.0)$ & $-13.9 \%$ & -114.0 & $(30.3)$ & $-59.0 \%$ \\
$04 / 27-05 / 04$ & -929.0 & $(97.0)$ & $-11.8 \%$ & -33.0 & $(30.3)$ & $-26.1 \%$ \\
$05 / 05-05 / 10$ & -753.0 & $(97.0)$ & $-10.1 \%$ & -120.6 & $(30.3)$ & $-46.8 \%$ \\
$05 / 11-05 / 18$ & -684.0 & $(97.0)$ & $-8.6 \%$ & -129.2 & $(30.3)$ & $-43.6 \%$ \\
$05 / 19-05 / 24$ & -520.7 & $(97.0)$ & $-7.2 \%$ & -65.0 & $(30.3)$ & $-27.4 \%$ \\
$05 / 25-05 / 31$ & -499.0 & $(97.0)$ & $-6.8 \%$ & 5.2 & $(30.3)$ & $2.7 \%$ \\
\hline Total & -10322.2 & & $-11.4 \%$ & -1172.4 & & $-41.5 \%$ \\
\hline
\end{tabular}

Notes: This table shows weekly demand and emissions reductions in GWh, predicted using FNet. Standard errors are reported in parentheses. They are constant across week because the covariance matrix account for error correlation across hours of a given day, but not across days, or week.

New daily load patterns. As teleworking became the new normal and public transportation was shutdown, new daily load patterns have emerged. Table 4 reports the average estimates of relative demand reduction by time of the day from 03/24 to $05 / 04$. In relative terms, the largest consumption reduction occurs during the morning peak with $-18.4 \%$ during weekdays and $-13.3 \%$ during week-ends.

Table 4: Average daily load reductions (weekdays)

\begin{tabular}{lcccc}
\hline \hline & Night & Morning & Afternoon & Evening \\
\hline Weekdays & $-10.7 \%$ & $-18.4 \%$ & $-14.2 \%$ & $-13.3 \%$ \\
& $(1.1)$ & $(1.1)$ & $(1.0)$ & $(1.1)$ \\
Week-ends & $-8.9 \%$ & $-13.3 \%$ & $-9.6 \%$ & $-9.5 \%$ \\
& $(1.2)$ & $(1.5)$ & $(1.3)$ & $(1.3)$ \\
\hline
\end{tabular}

Notes: This table shows average load reductions in relative terms caused by lockdown measures, separately for weekdays and weekends. Standard errors, taking account of the correlation of hourly errors within a day, are reported in parentheses.

The consumption timing has also changed. Figures $5 \mathrm{a}$ and $5 \mathrm{~b}$ show the average 
loads (actual and counterfactual) for weekdays and week-ends. Lockdown measures shaved the morning and evening peaks during weekdays. During week-ends, morning consumption increased more sharply than usual, suggesting that sheltering measures have affected sleeping and consumption patterns.

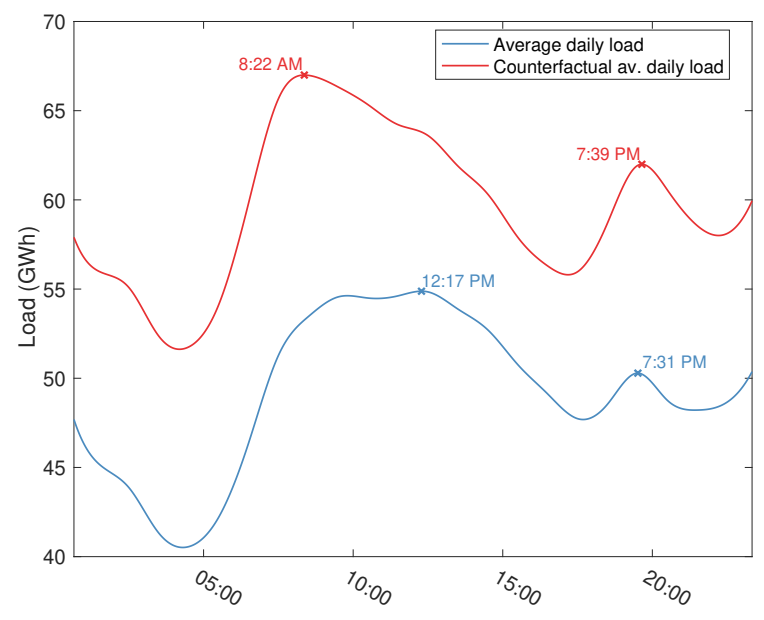

(a) Daily load patterns (weekdays)

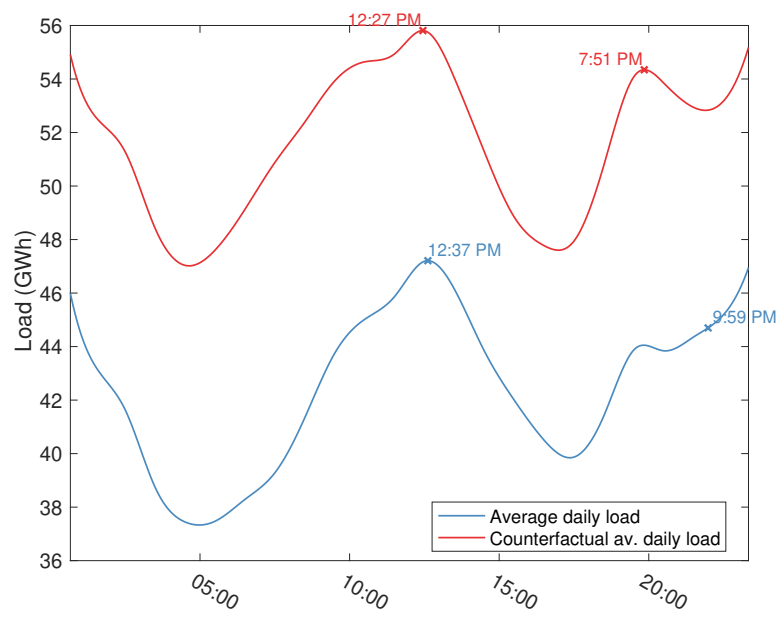

(b) Daily load patterns (weekends)

\section{Measuring market impacts}

In this section, we develop a methodology to estimate the impacts of demand reductions and natural gas price reductions on the day-ahead market. This approach follows similar steps than Benatia (2020b) for New York. The main additions are that we address the endogeneity of prices and we endogenize cross-border exchanges with adjacent electricity systems. Market-coupling is a key component of European electricity markets as prices are settled altogether in a common dispatch algorithm. It is thus crucial to account for cross-border exchanges. Summary statistics of the main variables used in this analysis are presented in Table 5. 
Table 5: Summary statistics

\begin{tabular}{lccccc}
\hline \hline & Price & Net Imports & Wind FR & Production & Nat.gas price \\
\hline Mean & 41.0 & -6821.8 & 3656.0 & 12.2 & 16.3 \\
Std & 18.6 & 4126.9 & 2703.8 & 5.2 & 6.7 \\
1st percentile & 2.3 & -14488.2 & 515.9 & 2.6 & 3.7 \\
99th percentile & 86.1 & 4867.9 & 12006.8 & 25.8 & 29.2 \\
\hline
\end{tabular}

Notes: This table shows means, standard deviations, 99th percentile and 1st percentile for the Day-ahead price (in $€ / M W h$ ), net imports (in MW), wind power production in France (MW), domestic production (in $\mathrm{GW}$ ), and natural gas prices (in $€ / M M B t u$ ).

\subsection{Net import curve}

The European electricity market is a zonal market with multiple trading zones, each covering an entire country or spreading over a larger region, and with limited exchange capacities between zones. The French electricity system consists in a single trading zone interconnected to the rest of the European system through interfaces with Belgium, Germany, Italy, Spain, Switzerland, and the United Kingdom.

We aim at estimating the net import function, that is how net imports of electricity in France vary with the local day-ahead price. In order to simplify the analysis, we focus on the aggregate net imports across all six interfaces. Our methodology is inspired by previous papers in the economics literature, e.g. Brown and Olmstead (2017).

Specification. Let $I_{t}$ be the net imports at time $t, P_{t}^{D A}$ be the Day-ahead (DA) price in France, and $Z_{t}$ be exogenous covariates in other countries. In a general equilibrium model, $I_{t}$ results from a system of price equations. We follow a partial equilibrium approach by focusing only on France. We specify the net import curve as the linear function of prices given by

$$
I_{t}=\beta_{I} P_{t}^{D A}+\gamma_{I} Z_{t}+\varepsilon_{t},
$$

where $\varepsilon_{t}$ is a mean-zero error term, and the parameters of interest are $\beta_{I}$ and $\gamma_{I}$.

$\beta_{I}$ captures the effect of an increase in the local spot price (i.e. in France) on net imports. It corresponds to the slope of the net imports curve. We expect this parameter to be positive: as the local price increases it is more likely that foreign countries find 
profitable to export to France. Reversely, as the price decreases, other countries may find profitable to import electricity produced in France, which would increase exports (hence reduce net imports) in France.

$\gamma_{I} Z_{t}$ measures the extent to which other countries are willing to export to France, accounting only for their own demand and supply conditions and independently of the French price. It corresponds to the intercept of the net imports curve. This term is important to obtain credible counterfactual prices because other countries have also been affected by the crisis. More specifically, their demand for electricity produced in France may have differed from business-as-usual not only because of the effect of the crisis on the French price, but also due to its effects on their local demand.

The variables in $Z_{t}$ include temperature in trading countries (measured in Barcelona, Brussels, Frankfurt, Geneva, London, Turin), as well as renewable power forecasts (solar, onshore wind and offshore wind) from each of the six regions, and expected interconnection capacity limits with Italy, Spain, Switzerland and the United Kingdom (in both directions). ${ }^{10}$ In addition, we include a set of time dummies for hours of the day, days of the week, months, bank holidays in France and a linear time trend, leading to a total of 83 variables.

Identification. The identification of $\beta_{I}$ and $\gamma_{I}$ requires that the error $\varepsilon_{t}$ be uncorrelated with $P_{t}^{D A}$ and $Z_{t}$. The former condition is violated since $P_{t}^{D A}$ is simultaneously determined with $I_{t}$ in equilibrium. To solve this endogeneity problem, we pursue an instrumental variable (IV) approach. A valid IV affects $I_{t}$ only through $P_{t}^{D A}$, the local price. We opt for wind power production in France which affects the price in France through the merit-order effect, but does not affect (or is not correlated with) demand or supply conditions in other countries - as long as one controls for foreign renewable power production and weather conditions. We consider it to be more suitable than local weather conditions for instrumentation because temperature, for example, is likely to be strongly correlated across countries. Thus, using local weather as an instrument while controlling for foreign weather conditions would leave little identifying variations. In comparison, domestic wind power production is less predictable and tends to be much less correlated to foreign weather and renewable outputs.

\footnotetext{
${ }^{10}$ This information is not available for Belgium and Germany on ENTSO-E transparency.
} 
Estimation. Model (1) is estimated using least-squares and two-step IV-GMM on hourly observations from January 1, 2018 to February 28, 2020. The weighting matrix used for those estimations corresponds to the Newey-West covariance matrix robust to arbitrary autocorrelation and heteroskedasticity, including 24 hourly lags.

Table 6 shows the estimation results of three regressions. The first column reports the estimates of (1) without correcting for the endogeneity of $P_{t}^{D A}$. The second column shows the estimates of the first-stage, that is the regression of $P_{t}^{D A}$ onto wind power in France $W$ ind.F $R$ and $Z_{t}$. The third column reports the coefficients of (1) while using Wind.FR as an IV for $P_{t}^{D A}$. We show only the 8 most significant coefficients associated with exogenous (and non-deterministic) covariates, as measured by their t-statistic from the IV regression.

The IV regression yields a significantly larger coefficient for $P_{t}^{D A}$ than least-squares, revealing a downward endogeneity bias. The first-stage results validate $W$ ind.FR as a good IV, in the sense that it is strongly correlated with $P_{t}^{D A}$, conditionally on covariates. Its coefficient is negative, which is in line with the well-known result that wind power tends to depreciate prices.

The most significant covariates, neglecting dummies, are transmission capacity from France to Italy, transmission capacity from France to Spain, and renewable power production in foreign countries. For instance, more export capacity to Italy decreases net imports, or more wind power generation in Germany increases net imports. 
Table 6: Estimates of the net import function

\begin{tabular}{|c|c|c|c|}
\hline Indep./Dep. & $\begin{array}{c}\text { Least-Squares } \\
\text { NetImports }\end{array}$ & $\begin{array}{c}\text { First-Stage } \\
\text { Price }\end{array}$ & $\begin{array}{c}\text { IV Reg. } \\
\text { NetImports }\end{array}$ \\
\hline Price (Endog.) & $\begin{array}{c} \\
0.09 \\
(0.01)\end{array}$ & & $\begin{array}{c}0.76 \\
(0.22)\end{array}$ \\
\hline Wind.FR $(I V)$ & & $\begin{array}{l}-1.50 \\
(0.46)\end{array}$ & \\
\hline TC.FR.IT & $\begin{array}{l}-0.72 \\
(0.08)\end{array}$ & $\begin{array}{c}0.75 \\
(0.31)\end{array}$ & $\begin{array}{l}-1.23 \\
(0.28)\end{array}$ \\
\hline Solar.IT & $\begin{array}{l}-0.68 \\
(0.14)\end{array}$ & $\begin{array}{c}2.14 \\
(0.45)\end{array}$ & $\begin{array}{l}-2.12 \\
(0.55)\end{array}$ \\
\hline WindOns.DE & $\begin{array}{c}0.82 \\
(0.11)\end{array}$ & $\begin{array}{l}-0.79 \\
(0.41)\end{array}$ & $\begin{array}{c}1.27 \\
(0.34)\end{array}$ \\
\hline WindOns.ES & $\begin{array}{c}0.37 \\
(0.07)\end{array}$ & $\begin{array}{l}-1.47 \\
(0.30)\end{array}$ & $\begin{array}{c}1.53 \\
(0.43)\end{array}$ \\
\hline SolarCH & $\begin{array}{c}0.65 \\
(0.15)\end{array}$ & $\begin{array}{l}-2.07 \\
(0.53)\end{array}$ & $\begin{array}{c}2.00 \\
(0.57)\end{array}$ \\
\hline TC.FR.ES & $\begin{array}{l}-0.27 \\
(0.08)\end{array}$ & $\begin{array}{c}2.40 \\
(0.29)\end{array}$ & $\begin{array}{l}-1.91 \\
(0.57)\end{array}$ \\
\hline WindOff.UK & $\begin{array}{c}0.51 \\
(0.15)\end{array}$ & $\begin{array}{l}-4.47 \\
(0.53)\end{array}$ & $\begin{array}{c}3.52 \\
(1.05)\end{array}$ \\
\hline Solar.BE & $\begin{array}{c}0.54 \\
(0.16)\end{array}$ & $\begin{array}{l}-1.69 \\
(0.50)\end{array}$ & $\begin{array}{c}1.64 \\
(0.50)\end{array}$ \\
\hline Dummies & \multicolumn{3}{|c|}{ Hours/Weekdays/Month + Linear Time Trend } \\
\hline \# Covariates & 84 & 84 & 84 \\
\hline Obs & 18818 & 18818 & 18818 \\
\hline RMSE & 2.7 & 9.9 & 7.2 \\
\hline
\end{tabular}

Notes: This table reports regression results for the net import function specified in (1) using FGLS (column 1), first-stage of $P_{t}^{D A}$ onto Wind.FR as IV (column 2) and IV-GMM of (1). Standard errors are computed using the Newey-West covariance estimator with 24 lags. They are robust to arbitrary heteroskedasticity and autocorrelation. Covariates include forecasted transfer capacities by interconnector, renewable production forecasts by trading country, and dummies for hours of the day, days of the week, months, bank holidays in France and a linear time trend. The last row reports the root-mean-squared-error (RMSE). 


\subsection{Day-ahead market}

The day-ahead prices across Europe are computed by a single algorithm called "Euphemia", ${ }^{11}$ maximizing the overall welfare. The algorithm then gives prices for each zone, for each hour of the following day, as well as implicitly allocating auction-basedcross-border capacities. The prevailing hourly price, for a given zone, corresponds approximately to the price bid of the generation unit called into operation with the highest-accepted bid price. Under perfect competition, this price coincides with the unit's marginal cost of production. In practice, price bids include mark-ups or markdowns depending on the firm's forward position and ability to exercise market power.

Let us specify the aggregate supply as

$$
P_{t}^{D A}=\beta_{Q} Q_{t}+\beta_{N} N_{t}+\delta N G_{t}+\rho Z_{t}^{D}+\xi_{t}
$$

which is a linear function of thermal and hydro production $Q_{t}$, nuclear production $N_{t}$, natural gas prices $N G_{t}$, additional covariates $Z_{t}^{D}$, and a zero-mean error term $\xi_{t}$. This specification corresponds to a piecewise linear supply function with two technologies: nuclear plants $N_{t}$, and thermal and hydro plants $Q_{t}=D_{t}-N_{t}-I_{t}-R_{t}$, with $D_{t}$ being demand, $I_{t}$ being net imports and $R_{t}$ being renewable output. The exogenous covariates $Z_{t}^{D}$ are the same as in (1), except for cross-border transmission capacities.

Model (2) admits a structural interpretation following Wolfram (1999). The average of the first-order condition of firm-level profit-maximization problems across firms yields the industry-level supply relationship $P_{t}^{D A}=\alpha M C$ where $M C$ denote the industrylevel marginal cost function and $\alpha$ is a behavioral parameter depending on the degree of competition. A piecewise linear specification for $M C$ directly yields (2), where parameters implicitly depend on the degree of competition. We remain agnostic about the degree of competition, which does not matter for this paper's main objective, and thereby neglect the identification of $\alpha$.

Identification. The identification of $\beta_{Q}$ and $\beta_{N}$ suffers from the simultaneity of $P_{t}^{D A}$ with $Q_{t}$ and $N_{t}$. On one hand, the realized price depends on the respective production

\footnotetext{
${ }^{11}$ Single Price Coupling Algorithm public description (10/04/2019) at http://www . nemo-committee.eu/publications,
} 
of each sector (thermal, nuclear and hydro) and the volume of net imports through the equilibrium mechanism: an increase of production means a larger price. At the same time, strategic players form expectations about the realized price upon choosing their bids. Thus, the way the price depends on strategic bids which themselves dependent on expectations about the price. ${ }^{12}$

We instrument $Q_{t}$ and $N_{t}$ with Wind.FR and Solar.FR, the wind and solar power production in France. Both are valid IV because they affect the equilibrium price only indirectly through their effects on conventional generation. More specifically, renewable power is produced at near-zero marginal cost and benefits from priority dispatch. Therefore it reduces the amount of energy to be produced by conventional generation (thermal, hydro and nuclear plants) in equilibrium, everything else kept constant.

Estimation. Model (2) is estimated using the same approach as model (1). Table 7 shows the estimation results of four regressions. The first column neglects the endogeneity issue. The second column shows the estimates of the first-stage for $Q_{t}$. The third column shows the estimates of the first-stage for $N_{t}$ The fourth column reports the coefficients of (2) when accounting for the endogeneity of $Q_{t}$ and $N_{t}$. We report only the 6 most significant coefficients associated with exogenous (non-deterministic) covariates, as measured by their t-statistic from the IV regression.

\footnotetext{
${ }^{12}$ Note that here we use realized outputs by technology rather than expectations. The variables are hence subject to measurement errors. This is not an issue assuming those errors are orthogonal to spot prices.
} 
Table 7: Regression results DAM

\begin{tabular}{|c|c|c|c|c|}
\hline Indep./Dep. & $\begin{array}{c}\text { Least-Squares } \\
\text { Price }\end{array}$ & $\begin{array}{c}\text { First-Stage } \\
Q_{t} \\
\end{array}$ & $\begin{array}{c}\text { First-Stage }(\mathrm{N}) \\
N_{t} \\
\end{array}$ & $\begin{array}{c}\text { IV Reg. } \\
\text { Price }\end{array}$ \\
\hline$Q_{t}($ End. $)$ & 1.13 & & & 2.20 \\
\hline & $(0.07)$ & & & $(0.27)$ \\
\hline$N_{t}($ End. $)$ & $\begin{array}{c}0.82 \\
(0.07)\end{array}$ & & & $\begin{array}{c}1.23 \\
(0.54)\end{array}$ \\
\hline Wind.FR $(I V)$ & & $\begin{array}{l}-1.51 \\
(0.19)\end{array}$ & $\begin{array}{c}0.76 \\
(0.21)\end{array}$ & \\
\hline Solar.FR $(I V)$ & & $\begin{array}{l}-0.96 \\
(0.11)\end{array}$ & $\begin{array}{l}-0.41 \\
(0.13)\end{array}$ & \\
\hline Nat. Gas Price & $\begin{array}{c}1.96 \\
(0.08)\end{array}$ & $\begin{array}{l}-0.04 \\
(0.02)\end{array}$ & $\begin{array}{c}0.06 \\
(0.02)\end{array}$ & $\begin{array}{c}1.99 \\
(0.10)\end{array}$ \\
\hline Temp.CH & $\begin{array}{c}1.24 \\
(0.41)\end{array}$ & $\begin{array}{l}-0.31 \\
(0.12)\end{array}$ & $\begin{array}{l}-0.13 \\
(0.15)\end{array}$ & $\begin{array}{c}1.61 \\
(0.44)\end{array}$ \\
\hline Temp.ES & $\begin{array}{l}-2.29 \\
(0.50)\end{array}$ & $\begin{array}{l}-0.11 \\
(0.15)\end{array}$ & $\begin{array}{c}-0.53 \\
(0.17)\end{array}$ & $\begin{array}{l}-1.97 \\
(0.59)\end{array}$ \\
\hline WindOns.BE & $\begin{array}{l}-1.99 \\
(0.32)\end{array}$ & $\begin{array}{l}-0.08 \\
(0.13)\end{array}$ & $\begin{array}{c}0.03 \\
(0.16)\end{array}$ & $\begin{array}{l}-1.03 \\
(0.39)\end{array}$ \\
\hline WindOns.UK & $\begin{array}{c}0.79 \\
(0.24)\end{array}$ & $\begin{array}{l}-0.40 \\
(0.08)\end{array}$ & $\begin{array}{c}0.57 \\
(0.09)\end{array}$ & $\begin{array}{c}0.99 \\
(0.39)\end{array}$ \\
\hline WindOff.UK & $\begin{array}{l}-1.32 \\
(0.36)\end{array}$ & $\begin{array}{c}0.56 \\
(0.13)\end{array}$ & $\begin{array}{l}-0.86 \\
(0.15)\end{array}$ & $\begin{array}{l}-1.56 \\
(0.64)\end{array}$ \\
\hline Dummies & Hours/Week & s/Month + & ear Time Trend & \\
\hline \# Covariates & 80 & 80 & 80 & 80 \\
\hline Obs & 18818 & 18818 & 18818 & 18818 \\
\hline RMSE & 7.7 & 2.4 & 2.4 & 8.1 \\
\hline
\end{tabular}

Notes: This table reports regression results for the supply function specified in (2) using FGLS (column 1), first-stage of $P_{t}^{D A}$ onto Wind.FR as IV (column 2) and IV-GMM of (2). Standard errors (in parentheses) and weighting matrix are based on the Newey-West covariance estimator with 24 lags. Standard errors are robust to arbitrary heteroskedasticity and autocorrelation. Covariates include temperature and renewable production forecasts for the six interconnected countries, and dummies for hours of the day, days of the week, months, bank holidays in France and a linear time trend. The last row reports the root-mean-squared-error (RMSE).

The first-stage regressions confirm that thermal and hydro productions are substituted by intermittent renewables. Nuclear generation is also found to be negatively correlated with wind power but not solar power. This positive coefficient is likely to be explained by the correlation of solar and nuclear power generations through the diurnal 
and seasonal patterns of electricity demand.

The coefficients for $Q_{t}$ and $N_{t}$ in the IV regression are larger than when neglecting endogeneity. Furthermore, the coefficient associated with $N_{t}$ is smaller than that of $Q_{t}$. Nuclear plants have typically smaller marginal costs than thermal and hydro plants. The estimated aggregate supply function hence becomes steeper as domestic generation increases and more thermal and hydro units enter into production. Natural gas prices also turn out to have a significantly positive effect on prices.

\subsection{Counterfactual scenarios}

In this section, we investigate 4 counterfactual scenarios. The first 3 scenarios are focused on the short-run effects of the crisis. Scenario 1 evaluates the impacts of the electricity demand reductions caused by containment measures. Scenario 2 measures the impacts of the decrease in natural gas prices observed globally. Scenario 3 combines the above two effects.

Scenario 4 is used to draw insights about the sustainability of the industry in the longer run. It studies the role of renewables in the consequences of the crisis. We assume the event occurred with wind and solar power up to $40 \%$ of electricity production and nuclear generation down to $50 \%$, which correspond to the 2030 environmental targets for France.

For clarity, we use the standard notations of the potential outcomes framework, where variables indexed by (1) have received the treatment and those indexed by (0) have not. The treatment under study varies across scenarios.

Counterfactual scenario 1: Lockdown. First, we study the impact of demand reductions using our estimates of the counterfactual demand obtained in Section 2. The counterfactual DA price assuming that demand reductions due to containment measures had not occurred is given by

$$
\begin{aligned}
\widehat{P}_{t}^{D A}(0)= & P_{t}^{D A}(1)+\hat{\beta}_{Q}\left[\left(\widehat{D}_{t}^{D A}(0)-\widehat{N}_{t}(0)-\widehat{I}_{t}(0)-R_{t}\right)-\left(D_{t}^{D A}(1)-N_{t}-I_{t}(1)-R_{t}\right)\right] \\
& +\hat{\beta}_{N}\left[\widehat{N}_{t}(0)-N_{t}\right]
\end{aligned}
$$


where $\widehat{P}_{t}^{D A}(0)$ is the counterfactual DA price, $\widehat{D}_{t}^{D A}(0)$ and $\widehat{N}_{t}(0)$ are the estimated counterfactual demand and nuclear generation using FNet, and $\widehat{I}_{t}(0)$ is the counterfactual net imports. On the other hand, $P_{t}^{D A}(1), D_{t}^{D A}(1), N_{t}(1)$ and, $I_{t}(1)$ are the observed realizations. Rearranging the above expression yields

$\widehat{P}_{t}^{D A}(0)=P_{t}^{D A}(1)+\hat{\beta}_{Q}\left[\left(\widehat{D}_{t}^{D A}(0)-\left(D_{t}^{D A}(1)+I_{t}(1)-\widehat{I}_{t}(0)\right]+\left(\hat{\beta}_{N}-\hat{\beta}_{Q}\right)\left[\widehat{N}_{t}(0)-N_{t}\right]\right.\right.$,

and making use of (1) gives the following closed-form expression of the counterfactual price

$$
\begin{aligned}
\widehat{P}_{t}^{D A}(0)= & \frac{P_{t}^{D A}(1)}{1+\hat{\beta}_{Q} \hat{\beta}_{I}}+\frac{\hat{\beta}_{Q}}{1+\hat{\beta}_{Q} \hat{\beta}_{I}}\left[\widehat{D}_{t}^{D A}(0)-D_{t}^{D A}(1)+I_{t}(1)-\hat{\gamma}_{I} Z_{t}\right] \\
& +\frac{\hat{\beta}_{N}-\hat{\beta}_{Q}}{1+\hat{\beta}_{Q} \hat{\beta}_{I}}\left[\widehat{N}_{t}(0)-N_{t}\right] .
\end{aligned}
$$

Counterfactual scenario 2: Natural gas. Second, we study the impact of the natural gas price reductions by assuming a counterfactual price equal to the average during January to February 2020. All other variables are kept unchanged. Figure 6 shows the time-series of natural gas prices $N G_{t}(1)$ and its counterfactual $N G_{t}(0)$. The counterfactual price is given by

$$
\begin{aligned}
\widehat{P}_{t}^{D A}(0) & =P_{t}^{D A}(1)+\hat{\beta}_{Q}\left[I_{t}(1)-\widehat{I}_{t}(0)\right]+\hat{\delta}\left[N G_{t}(0)-N G_{t}(1)\right] \\
& =\frac{P_{t}^{D A}(1)}{1+\hat{\beta}_{Q} \hat{\beta}_{I}}+\frac{\hat{\beta}_{Q}}{1+\hat{\beta}_{Q} \hat{\beta}_{I}}\left[I_{t}(1)-\hat{\gamma}_{I} Z_{t}\right]+\frac{\hat{\delta}}{1+\hat{\beta}_{Q} \hat{\beta}_{I}}\left[N G_{t}(0)-N G_{t}(1)\right] .
\end{aligned}
$$




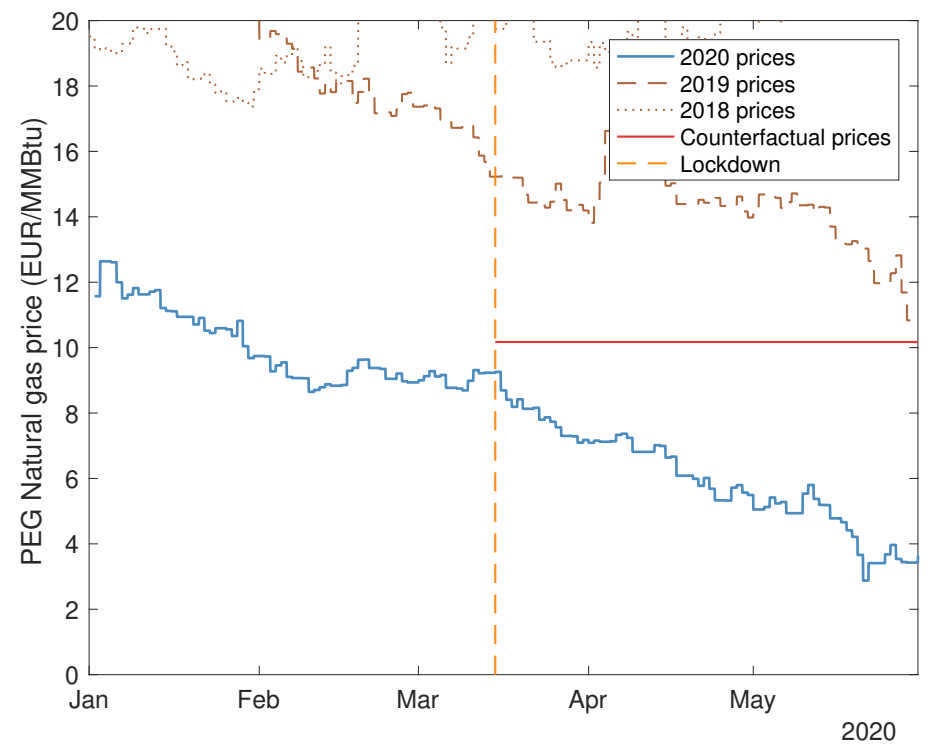

Figure 6: Natural gas prices

Counterfactual scenario 3: Lockdown and natural gas. In this scenario, we combine (3) and (4) to obtain the counterfactual price assuming the crisis did not affect energy markets:

$$
\begin{aligned}
\widehat{P}_{t}^{D A}(0)= & \frac{P_{t}^{D A}(1)}{1+\hat{\beta}_{Q} \hat{\beta}_{I}}+\frac{\hat{\beta}_{Q}}{1+\hat{\beta}_{Q} \hat{\beta}_{I}}\left[\widehat{D}_{t}^{D A}(0)-D_{t}^{D A}(1)+I_{t}(1)-\hat{\gamma}_{I} Z_{t}\right] \\
& +\frac{\hat{\beta}_{N}-\hat{\beta}_{Q}}{1+\hat{\beta}_{Q} \hat{\beta}_{I}}\left[\widehat{N}_{t}(0)-N_{t}\right]+\frac{\hat{\delta}}{1+\hat{\beta}_{Q} \hat{\beta}_{I}}\left[N G_{t}(0)-N G_{t}(1)\right] .
\end{aligned}
$$

Counterfactual scenario 4: Renewable targets. What would have been the consequences of the crisis if Europe had already reached its ambitious renewable targets set for 2030? We believe an answer to this question would shed light on the sustainability of future highly-renewable electricity markets in the face of disruptive events such as the COVID-19 crisis. In this scenario, demand is held at the realized "crisis level": $D_{t}(0)=D_{t}(1)$.

In 2030, all European countries would have increased their renewable capacity and so increasing exports would not be an available option for France to integrate its domestic renewable power. We formalize this idea by assuming cross-border exchanges 
to remain as observed, i.e. $I_{t}(0)=I_{t}(1)$. Since this is a partial equilibrium model where foreign countries are not explicitly modelled, and cross-border transfer capacities are held as observed, this assumption allows to prevent exports from increasing dramatically as a consequence of even lower local prices.

France's objective for 2030 is to have $40 \%$ of domestic generation from renewable sources and 50\% from nuclear energy. From January to May 2020, renewable and nuclear energy accounted for, respectively $25 \%$ and $68 \%$ of domestic production. In order to reach this target, wind and solar power should increase from $11 \%$ to $25 \%$ of total generation while keeping hydro and biomass generation fixed at $14 \%$. At the same time, nuclear generation would have to reduce down by 18 points.

The counterfactual price is obtained using the same approach as before

$$
\begin{aligned}
\widehat{P}_{t}^{D A}(0) & =P_{t}^{D A}(1)+\hat{\beta}_{Q}\left[\left(-\frac{0.5}{0.68} N_{t}-\frac{0.25}{0.11} R_{t}\right)-\left(-N_{t}-R_{t}\right)\right]+\hat{\beta}_{N}\left[\frac{0.5}{0.68} N_{t}-N_{t}\right] \\
& =P_{t}^{D A}(1)-\frac{0.14}{0.11} \hat{\beta}_{Q} R_{t}+\frac{0.18}{0.68}\left(\hat{\beta}_{Q}-\hat{\beta}_{N}\right) N_{t} .
\end{aligned}
$$

\subsection{Price impacts and net imports}

The above prices are calculated together with their corresponding net imports, for all hours from March 1 to May 31, 2020. We then use those estimates to compute the gross value of the day-ahead market in each scenario.

Day-ahead prices. Weekly average price impacts are reported in Table 8 for all five scenarios. Price impacts are calculated as

$$
\Delta P=P_{t}^{D A}(1)-\widehat{P}_{t}^{D A}(0)
$$

that is a negative value indicates that the observed prices were (on average) lower than their corresponding counterfactual levels in any given scenario. 
Table 8: Average price impacts (€/MWh)

\begin{tabular}{lcccc}
\hline \hline & Lockdown & Nat. gas & Lockd./Gas & Renew. \\
\hline $03 / 16-03 / 22$ & -5.72 & -5.17 & -9.87 & 4.30 \\
$03 / 23-03 / 29$ & -7.00 & -7.13 & -12.00 & 10.91 \\
$03 / 30-04 / 05$ & -9.61 & -8.01 & -13.03 & 8.10 \\
$04 / 06-04 / 12$ & -6.52 & -5.33 & -9.64 & 2.21 \\
$04 / 13-04 / 19$ & -7.29 & -5.74 & -11.06 & 5.81 \\
$04 / 20-04 / 26$ & -2.77 & -5.02 & -8.57 & 2.63 \\
$04 / 27-05 / 04$ & -5.53 & -6.93 & -10.37 & 9.00 \\
$05 / 05-05 / 10$ & -3.82 & -7.21 & -9.48 & 4.01 \\
$05 / 11-05 / 18$ & -4.45 & -8.32 & -10.03 & 10.94 \\
$05 / 19-05 / 24$ & -3.69 & -10.37 & -11.20 & 5.86 \\
$05 / 25-05 / 31$ & -4.18 & -10.81 & -11.45 & 8.37 \\
Average & -5.51 & -7.28 & -10.61 & 6.56 \\
\hline
\end{tabular}

Notes: This table shows weekly average price impacts in $€ / M W h$ after March 16th, 2020, when the lockdown was implemented in France. We report estimates for the five counterfactual scenarios presented earlier. The averages across all hours are given in the last row.

The average DA price observed during this period was about $15 € / \mathrm{MWh}$. Contaiment measures alone are found to have caused an average price decrease of about $5 € / \mathrm{MWh}$ (column 1), which corresponds to a $25 \%$ decrease with respect to the average counterfactual price of $20 € / M W h$. The strongest price impacts occurred during the first weeks of the lockdown. The price of natural gas has also had a significant impact. We find that, on average, prices would have been about $7 € /$ MWh higher in absence of fuel price reductions (column 2). This effect is larger in May since the fuel price has gradually decreased from February onwards. The combination of those two effects yields an average price impact of the crisis of about $10.5 € / \mathrm{MWh}$ (column 3 ), i.e. a decrease above $40 \%$ with respect average prevailing price of $25.5 € / \mathrm{MWh}$ had the crisis not occurred.

In the 2030 scenario with increased penetration of renewables, the consequences of the crisis are even stronger. Prices would have been reduced by an extra $6.5 € / \mathrm{MWh}$ (column 4), down to an average of $8.5 € / \mathrm{MWh}$ only. Therefore, increasing the deployment of renewable energy without market design adjustments dampens the economic sustainability of the system, not only by reducing average prices in normal conditions but also by making it less resilient to highly disruptive events. 
Figure 7 shows the actual and counterfactual prices in scenarios 1 and 3 . We note that the model is able to replicate observed prices fairly well in early March before the crisis. Note that neither the demand prediction model nor the IV regressions for net imports and aggregate supply use the observations during this period. We interpret this result as evidence of our model's external validity. This figure also reveals that the occurrences of negative prices would have been much less frequent had the crisis not occurred.

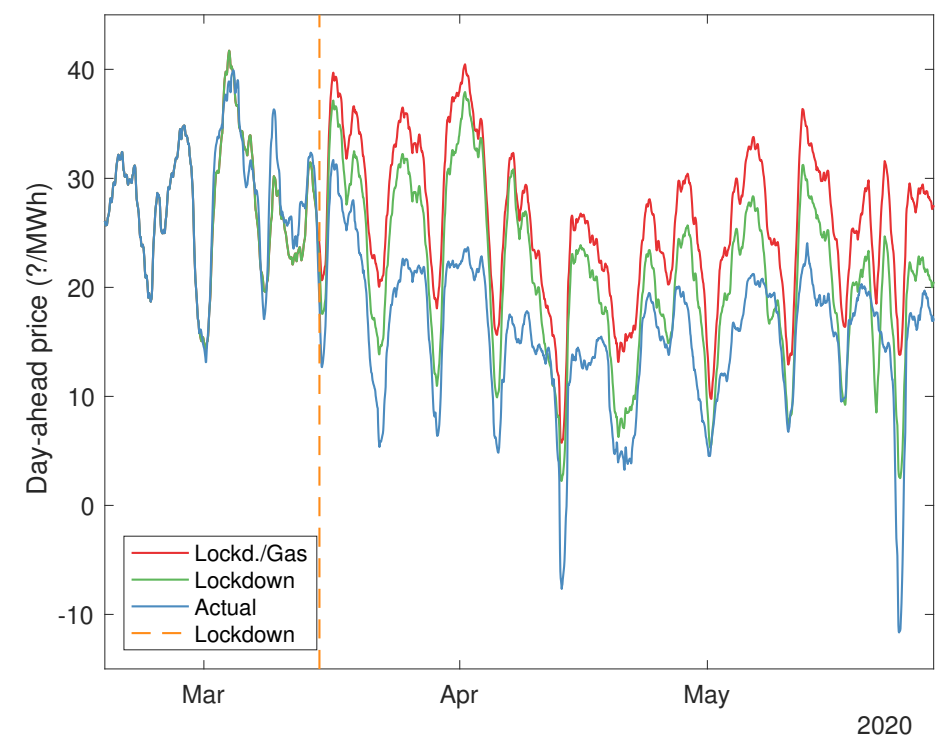

Figure 7: Actual and counterfactual day-ahead prices

Counterfactual imports. Weekly average impacts for net imports are reported in Table 9 for all five scenarios. We find that containment measures alone would have increased net imports by $1.4 \mathrm{TWh}$ in total. However, the entire effect of the crisis is obtained when also accounting for fuel prices. In this case, net imports are found to have actually decreased by about 5.6 TWh from mid-March to the end of May (column 3). During April alone, France seems to have increased its exports by 2.75 TWh because of the low price environment jointly caused by containment measures and the natural gas price reduction. 
Table 9: Impacts on net imports (GWh)

\begin{tabular}{lcccc}
\hline \hline & Lockdown & Nat. gas & Lockd./Gas & Renew. \\
\hline $03 / 16-03 / 22$ & 55.68 & 110.83 & -441.02 & 0.00 \\
$03 / 23-03 / 29$ & 165.44 & 146.50 & -466.21 & 0.00 \\
$03 / 30-04 / 05$ & -55.58 & 149.10 & -492.75 & 0.00 \\
$04 / 06-04 / 12$ & -218.33 & -70.32 & -617.32 & 0.00 \\
$04 / 13-04 / 19$ & -309.76 & -117.79 & -788.64 & 0.00 \\
$04 / 20-04 / 26$ & -18.79 & -305.67 & -760.29 & 0.00 \\
$04 / 27-05 / 04$ & -16.13 & -195.32 & -635.05 & 0.00 \\
$05 / 05-05 / 10$ & 202.98 & -206.56 & -495.96 & 0.00 \\
$05 / 11-05 / 18$ & 360.72 & -133.02 & -351.17 & 0.00 \\
$05 / 19-05 / 24$ & 563.82 & -201.39 & -306.48 & 0.00 \\
$05 / 25-05 / 31$ & 612.13 & -173.72 & -258.20 & 0.00 \\
Total & 1342.19 & -997.35 & -5613.08 & 0.00 \\
\hline
\end{tabular}

Notes: This table shows weekly average impacts on net imports in GWh after March 16th, 2020, when the lockdown was implemented in France. We report estimates for the five counterfactual scenarios presented earlier. The total across all hours are given in the last row.

Figure 8 shows the actual and counterfactual net imports in scenarios 1 and 3. As before, we note that the model is able to match the observed series reasonably well in early March before the crisis. This result provides an additional evidence of the model's external validity. 


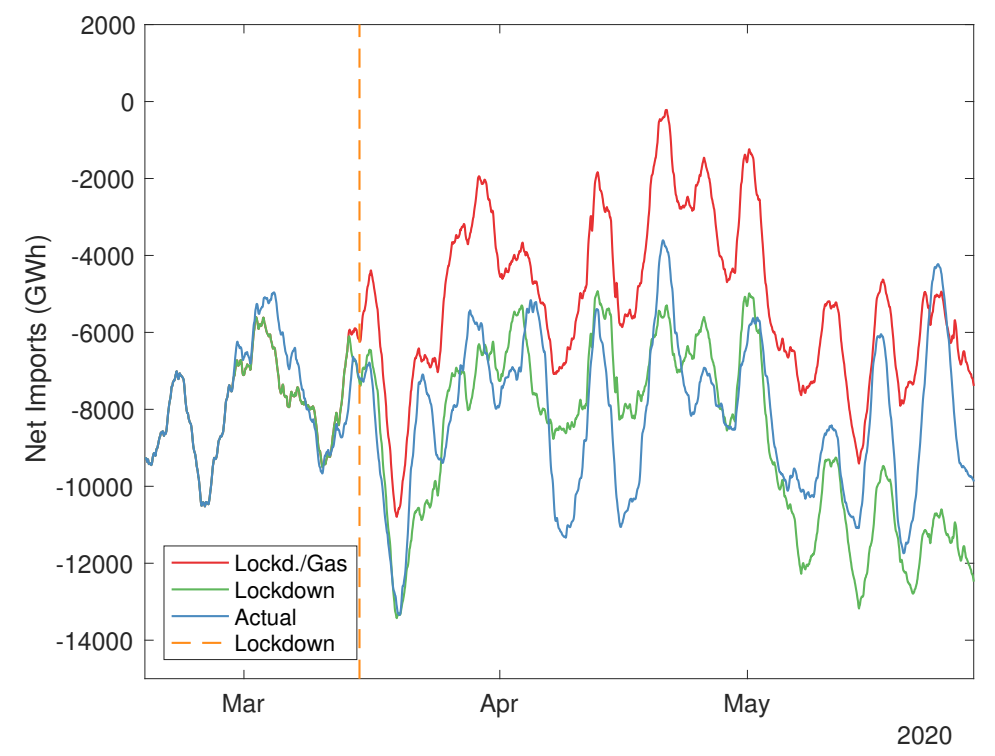

Figure 8: Actual and counterfactual imports

\subsection{Consequences for producers, retailers and grid operators}

We now use the previous results to measure the economic consequences for producers, retailers and grid operators.

Day-ahead market values. The value of the day-ahead market in every hour $t$ corresponds to the producers' gross revenues. It is defined as

$$
\text { Value }_{t}^{D A}=P_{t}^{D A} \times D_{t}^{D A} .
$$

Table 10 reports the actual day-ahead market value and its counterfactual values in each scenario. The total market value realized from March 16th to May 31st is 1.5 billion $€$ (column 1). Therefore, the joint effects of containment measures and fuel price drop are found to have caused a slump of $-45 \%$ in gross value from 2.7 billion $€$ (column 4). The marginal effects of sheltering measures and fuel prices are of similar magnitude (columns 2 and 3). The 2030 scenario reveals that gross revenues would have been further reduced by 500 million $€$ had renewable penetration been twice as large as today (column 5). 
Table 10: Weekly day-ahead market values (million $€$ )

\begin{tabular}{lccccc}
\hline \hline & Actual & Lockdown & Nat. gas & Lockd./Gas & Renew. \\
\hline $03 / 16-03 / 22$ & 214.9 & 303.4 & 265.1 & 335.5 & 197.6 \\
$03 / 23-03 / 29$ & 177.3 & 285.5 & 249.4 & 323.9 & 86.4 \\
$03 / 30-04 / 05$ & 185.7 & 312.3 & 265.2 & 335.3 & 121.4 \\
$04 / 06-04 / 12$ & 125.3 & 200.6 & 170.3 & 220.1 & 118.7 \\
$04 / 13-04 / 19$ & 87.9 & 162.0 & 130.2 & 186.1 & 42.7 \\
$04 / 20-04 / 26$ & 98.4 & 134.6 & 131.2 & 171.9 & 86.9 \\
$04 / 27-05 / 04$ & 104.3 & 169.5 & 159.3 & 199.5 & 30.4 \\
$05 / 05-05 / 10$ & 147.3 & 202.2 & 203.4 & 235.9 & 122.2 \\
$05 / 11-05 / 18$ & 154.0 & 217.8 & 225.3 & 253.2 & 57.2 \\
$05 / 19-05 / 24$ & 113.2 & 154.4 & 185.1 & 202.1 & 68.1 \\
$05 / 25-05 / 31$ & 122.9 & 175.9 & 205.2 & 221.2 & 55.5 \\
\hline Total & 1531.3 & 2318.3 & 2189.6 & 2684.8 & 987.1 \\
\hline
\end{tabular}

Notes: This table shows the total weekly DA market value in million $€$ for each counterfactual scenario after the lockdown. The last row reports the total values over the period.

Revenues impacts by sector. Our estimates allow to decompose revenues loss by sector. We propose to do so for scenarios 1 and 3, for which our counterfactual generations by sector remain plausible. Let us denote the observed production of thermal, nuclear and hydro plants by $T(1), N(1)$ and $H(1)$, respectively, and their counterfactual values predicted using FNet by $\widehat{T}(0), \widehat{N}(0)$ and $\widehat{H}(0)$. For internal consistency, we impose, at each time $t$, the equilibrium condition that the counterfactual demand $\widehat{D}^{D A}(0)$ equalizes the sum of productions and net imports $\widehat{I}_{i t}(0)$ for any scenario $i$. Thus, for each scenario $i$, we calculate the counterfactual thermal $\tilde{T}_{i t}$, nuclear $\tilde{N}_{i t}$ and hydro $\tilde{H}_{i t}$ generation as

$$
\tilde{X}_{i t}(0)=\Lambda_{i t} \widehat{X}_{t}(0), \quad \text { for } \quad X=T, N, H,
$$

where $\Lambda_{i t}=\frac{\widehat{D}_{t}^{D A}(0)-R_{t}-\widehat{I}_{i t}(0)}{\widehat{T}(0)+\widehat{N}(0)+\widehat{H}(0)}$. The average values (standard deviations) of $\Lambda_{i t}$ are 0.99 (0.06) and 0.93 (0.08) for scenario 1 and 3, using observations from March 1st to May 31st, 2020.

We consider the revenue of a production plant $X$, without hedging positions, to be the production volume times the difference between the DA price and the production $\operatorname{cost} K_{t}^{X}$. 
In the case of a thermal gas power plant, we consider the production cost to be

$$
K_{t}^{T}=\rho\left(\alpha N G_{t}+\beta C_{t}^{c a r b o n}\right)
$$

with $C_{t}^{\text {carbon }}=20 €$ the carbon price (this value is around the mean EUA emission price during the lockdown, source: ICE) and $\alpha=\frac{1}{0.52}, \beta=0.43$ characterizing the heat rate and emissions rate of the gas power plant, according to the Commission de régulation de l'énergie. ${ }^{13}$ This marginal cost is then multiplied by $\rho=0.65$, which corresponds to the share of gas-fired generation in the thermal mix.

In the case where there is no hedging positions, the revenues loss $L_{i t}^{T}$ at time $t$ in scenario $i$ with respect to the expectation for the thermal power plant is

$$
L_{i t}^{T}=T_{t}(1)\left(P_{t}^{D A}(1)-K_{t}^{T}(1)\right)-\tilde{T}_{i t}(0)\left(\widehat{P}_{i t}^{D A}(0)-\widehat{K}_{i t}^{T}(0)\right)
$$

with $\widehat{K}_{i t}(0)$ and $K_{t}(1)$ the counterfactual and observed production cost.

Concerning hydro production, we consider that the corresponding production cost is zero. Therefore the revenues loss for hydro technology is simply

$$
L_{i t}^{H}=P_{t}^{D A}(1) H_{t}(1)-\widehat{P}_{i t}^{D A}(0) \tilde{H}_{i t}(0) .
$$

For nuclear production, we consider a constant production cost $K_{t}^{N}=12 € / \mathrm{MWh}$ as proposed in Alasseur and Féron (2018), and we analyse the revenue variation for the production not involved in ARENH mechanism. Therefore we take into account the French ARENH contract by deducting the ARENH volume $V_{t}^{A R E N H}$ which were auctioned at the end of 2019 from the production :

$$
L_{i t}^{N}=\left(N_{t}(1)-V_{t}^{A R E N H}\right)\left(P_{t}^{D A}(1)-K_{t}^{N}\right)-\left(\tilde{N}_{i t}(0)-V_{t}^{A R E N H}\right)\left(\widehat{P}_{i t}^{D A}(0)-K_{t}^{N}\right)
$$

Considering that the global yearly ARENH volume contracted for 2020 is $100 \mathrm{TWh}$, we set $V_{t}^{A R E N H}=21.09 \mathrm{TWh}$ as the proportion of $100 \mathrm{TWh}$ corresponding to the 11 weeks of lockdown.

In the scenarios considered, renewable output remains constant. The change in

${ }^{13}$ https://www.cre.fr/Actualites/Rapport-de-surveillance-des-marches-de-gros-de-l-electricite-et-c 
revenues for renewable producers exposed to markets and not benefiting from any subsidies only comes from the price decrease, as given by

$$
L_{i t}^{R}=\left(P_{t}^{D A}(1)-\widehat{P}_{i t}^{D A}(0)\right) R_{t}(1)
$$

Now consider that producers have taken hedging position, assumed constant during all the lockdown period, up to a volume $\Delta^{X}$, the revenues loss $\bar{L}_{i t}^{X}(X=T, H, N$ or $R)$ is then defined as

$$
\bar{L}_{i t}^{X}=L_{i t}^{X}-\Delta^{X}\left(P_{t}^{D A}(1)-\widehat{P}_{i t}^{D A}(0)\right)
$$

In the numerical results, we consider a hedging position equal to the average of the expected production over the lockdown period, i.e. average production in scenario 3 which is the scenario producers anticipated when they took their hedging positions, as given by

$$
\Delta_{i}^{X}=\frac{1}{N_{h}} \sum_{t=1}^{N_{h}} \widehat{X}_{t}(0),
$$

with $N_{h}$ the number of hours of the whole lockdown period. One can rewrite equation (14):

$$
\begin{aligned}
\bar{L}_{i t}^{X}= & \left(X_{t}(1)-\widehat{X}_{i t}(0)\right)\left(\widehat{P}_{i t}^{D A}(0)-\widehat{K}_{t}^{X}(0)\right)-X_{t}(1)\left(K_{t}^{X}(1)-\widehat{K}_{t}^{X}(0)\right) \\
& -\left(\Delta^{X}-X_{t}(1)\right)\left(P_{t}^{D A}(1)-\widehat{P}_{i t}^{D A}(0)\right)
\end{aligned}
$$

The first term corresponds to the loss with respect to the expected revenue due to the diminution of the production. The second term corresponds to the loss due to changes in the production costs. This term is assumed to be zero for all considered producers, except for the gas power plant in scenarios 2 and 3, where this term is negative (the gas price is lower), leading to a reduced impacts on revenues. The last term is related to the combination of price and volume risks because there is a spread between the expected production volume $\Delta^{X}$ and the realized one $X_{t}(1)$. In the case of the COVID19 crisis, this last term is almost always negative because production had been lower than anticipated, and the price difference $\left(P_{t}^{D A}(1)-\widehat{P}_{i t}^{D A}(0)\right)$ is negative.

Table 11 shows weekly estimates of revenues impacts with respect to the expected revenue before the crisis for the two main scenarios. In absolute terms, the nuclear 
producer has been hit really hard with losses above 500 million $€$ (column 6). It corresponds to roughly 5\% of 2019 revenues for the nuclear sector. Nevertheless, the losses of the thermal and hydro sectors have been substantial. Hydro producers have lost $6.1 \%$ with respect to 2019 yearly revenues. For nuclear and hydro producers both gas price and demand reduction contributes to lower their revenue if they were completely exposed to spot prices. Table 11 shows that the gas price contraction helps to counterbalance the drop of demand and hence of production for thermal producers if they had not been hedged. Renewable expected revenue is also diminished even if the production remains the same in both scenarios. The impact for renewable is not supposed to impact all renewable producers but only those who are not benefiting from subsidies and are therefore directly exposed to the market. This is bound to happen in a very close future and is already the case for the oldest wind power plants.

Table 11: Weekly revenues impacts by sector (million $€$ )

\begin{tabular}{lcccccccc}
\hline \hline \multicolumn{1}{c}{ Lockdown } & \multicolumn{4}{c}{ Lockd./Gas } \\
\hline & Therm. & Nucl. & Hydr. & Ren. & Therm. & Nucl. & Hydr. & Ren. \\
$03 / 16-03 / 22$ & -5.6 & -35.0 & -9.2 & -5.9 & -6.0 & -52.3 & -13.2 & -9.9 \\
$03 / 23-03 / 29$ & -8.2 & -41.4 & -13.3 & -8.3 & -7.9 & -60.9 & -17.6 & -14.7 \\
$03 / 30-04 / 05$ & -10.7 & -54.4 & -14.0 & -10.4 & -7.9 & -66.3 & -16.5 & -14.7 \\
$04 / 06-04 / 12$ & -2.8 & -33.3 & -9.2 & -5.7 & -0.8 & -45.0 & -11.3 & -8.0 \\
$04 / 13-04 / 19$ & -2.2 & -29.9 & -9.3 & -8.5 & -0.4 & -43.8 & -11.9 & -12.0 \\
$04 / 20-04 / 26$ & 0.4 & -11.3 & -5.3 & -2.6 & 1.8 & -32.9 & -10.0 & -6.8 \\
$04 / 27-05 / 04$ & -2.2 & -26.7 & -9.4 & -5.9 & -0.4 & -42.7 & -13.3 & -10.9 \\
$05 / 05-05 / 10$ & -2.8 & -23.5 & -4.3 & -3.1 & -0.4 & -42.2 & -8.9 & -7.2 \\
$05 / 11-05 / 18$ & -3.6 & -26.5 & -4.8 & -5.7 & -0.8 & -44.9 & -9.4 & -11.8 \\
$05 / 19-05 / 24$ & -1.1 & -12.3 & -3.2 & -3.9 & 1.2 & -39.3 & -9.3 & -10.2 \\
$05 / 25-05 / 31$ & -2.0 & -21.0 & -3.7 & -4.1 & 0.7 & -45.8 & -9.2 & -11.2 \\
\hline Total & -41.0 & -315.4 & -85.8 & -64.1 & -20.9 & -516.2 & -130.6 & -117.3 \\
\hline
\end{tabular}

Notes: This table shows the weekly revenues loss by generation sector in million $€$ for each counterfactual scenario after the lockdown. The last row reports the total values over the period. 
Table 12: Weekly revenues loss, net of hedging contracts, by sector (million $€$ )

\begin{tabular}{lcccccccc}
\hline \hline & \multicolumn{4}{c}{ Lockdown } & \multicolumn{5}{c}{ Lockd./Gas } \\
\hline & Therm. & Nucl. & Hydr. & Ren. & Therm. & Nucl. & Hydr. & Ren. \\
$03 / 16-03 / 22$ & -1.1 & -9.0 & -1.9 & -0.4 & -1.1 & -7.4 & -0.6 & -0.3 \\
$03 / 23-03 / 29$ & -2.8 & -9.7 & -4.4 & -1.4 & -2.4 & -6.4 & -2.3 & -3.0 \\
$03 / 30-04 / 05$ & -3.2 & -10.7 & -1.8 & -1.1 & -2.3 & -7.1 & 0.1 & -2.0 \\
$04 / 06-04 / 12$ & 2.3 & -3.7 & -0.9 & 0.6 & 2.0 & -1.2 & 1.0 & 1.4 \\
$04 / 13-04 / 19$ & 3.4 & 3.2 & 0.0 & -1.4 & 2.7 & 6.4 & 2.2 & -1.2 \\
$04 / 20-04 / 26$ & 2.5 & 1.3 & -1.7 & 0.1 & 1.7 & 6.0 & 0.9 & 1.5 \\
$04 / 27-05 / 04$ & 2.1 & -1.6 & -2.3 & -0.5 & 0.5 & 4.3 & -0.0 & -0.8 \\
$05 / 05-05 / 10$ & 0.2 & -6.2 & 0.5 & 0.7 & -0.5 & 0.8 & 3.2 & 2.0 \\
$05 / 11-05 / 18$ & -0.1 & -6.3 & 0.9 & -1.4 & -0.5 & 0.6 & 3.4 & -2.1 \\
$05 / 19-05 / 24$ & 1.7 & 4.4 & 1.5 & -0.3 & 0.1 & 11.5 & 5.0 & 0.7 \\
$05 / 25-05 / 31$ & 1.2 & -2.1 & 1.6 & -0.0 & -0.2 & 6.2 & 5.4 & -0.1 \\
\hline Total & 6.2 & -40.3 & -8.5 & -5.2 & -0.1 & 13.7 & 18.2 & -3.8 \\
\hline
\end{tabular}

Notes: This table shows the weekly revenues loss by generation sector in million $€$ for each counterfactual scenario after the lockdown. The last row reports the total values over the period. Hedging contracts are estimated at the average production in scenario 3 (Lockd./Gas), which is considered business-as-usual.

Producers are bound to hedge their future production using derivative contracts. Accounting for future contracts leads to very different impacts of the COVID crisis on their expected revenues. Taking the hypothesis that they fully hedge their average future production, all producers manage to secure in a relative manner their expected revenue as the weekly revenues loss are now much lower, as shown in Table 12. They may even earn around 1\% more of what they expected as the difference between the realised and expected spot prices is so high that the last term in (14) counterbalances the impact of the diminution of production. This shows the importance and efficiency of hedging to secure future revenues even with the simple hedging strategy considered here. In that particular case, hedging manages to counterbalance the price risk as it is supposed to be but also the volume risk. This would have been different if the crisis has led to a drop of production combined with an increase of spot prices.

Grid operators: distribution networks. The cost structure of Enedis, the entity in charge of the distribution network in France, has variable (network losses and access rights to the transmission network) and fixed components (infrastructure management). 
Approximately $1 / 3$ of their annual costs comes from variable expenses and $2 / 3$ from fixed costs. ${ }^{14}$ In 2018, Enedis' expenses were evaluated at 13.5 billion $€$, of which 3.6 billion $€$ for transmission grid access rights (called "TURPE HTB") and 1 billion $€$ in compensation of network losses. Based on this evaluation, we can further refine the costs decomposition and state that the 2018 revenue of the distribution operator is decomposed as:

- $76 \%$ of fixed costs;

- $26.5 \%$ of transmission grid access rights which are proportional to the global consumption; and

- $7.5 \%$ of network losses which we consider proportional to the product of the consumption and the spot price.

The costs can be written as follows:

$$
\text { costs }=\text { fixed costs }+\underbrace{c_{1} \sum_{t} D_{t}^{D A}}_{\text {access rights }}+\underbrace{c_{2} \sum_{t} P_{t}^{D A} D_{t}^{D A}}_{\text {losses }}
$$

Using 2018 figures, we can estimate $c_{1}=7.5 € / \mathrm{MWh}$ and $c_{2}=4.210^{-2}$.

Because the power demand and the spot price were lower because of the COVID crisis, both the transmission grid access rights and the network losses diminsish. The diminution of costs induced by the sanitary crisis is then equal to:

- transmission grid access reduction : considering the estimated demand decrease to be on average $10821 \mathrm{GWh}$ and the assumed value of $c_{1}$ above, the transmission grid access reduction is estimated at $77.4 \mathrm{M} €$;

- network losses reduction : considering the estimated market values decrease to be $1150 \mathrm{M} €\left(\right.$ see Table 10) and the assumed value of $c_{2}$ above, the network losses reduction is estimated at $=48.4 \mathrm{M} €$.

\footnotetext{
${ }^{14}$ This information was obtained from Délibération N 2019-138 de la Commission de Régulation de l'Énergie of June 25th, 2019 on the evolution of access tariffs to public electricity networks.
} 
Revenue of the distribution grid operator come from a two-part tariff with a fixed part and variable part proportional to the realized energy consumption. But contrary to the cost structure (around 2/3 fixed and 1/3 variable), the revenue structure is such that only $27 \%$ of the annual revenues are fixed while $73 \%$ are variable. This implies that a diminution of the variable part mechanically induces a diminution of net revenues for the distribution grid operator. The revenue can also be written as follows:

$$
\text { revenues }=\text { fixed part }+\underbrace{r_{1} \sum_{t} D_{t}^{D A}}_{\text {variable part }}
$$

Using 2018 figures, and assuming that the revenue were equal to the costs (this is justified because the regulator adjusts the grid tariff so that the revenues of the distribution operator equals its cost), we estimate the parameter $r_{1}=20.7 € / \mathrm{MWh}$. The revenue diminution implied by the reduction of demand, estimated to be on average $10821 \mathrm{GWh}$, during the COVID crisis is therefore equal to $=217 \mathrm{M} €$.

As a result, the global impact for the distribution grid operator is a global reduction of its net revenue of $217-48.4-77.4=91.2 \mathrm{M} €$.

As already point out, this global negative impact on the net revenues is explained by the inverse ratios of fixed over variable components for costs and revenues. Information to evaluate financial impact of the crisis on the transmission grid operator (RTE) was not available but we can also expect a negative impact.

Retailers. Consider a retailer selling electricity at a fixed tariff $C$. Let us denote by $\widehat{Q}_{t}(0)$ and $Q_{t}(1)$ the counterfactual and observed retailer's sales to end-users for a given hour $t$. The revenues impacts of the retailer (without hedging) are

$$
\begin{aligned}
L_{t}^{Q} & =Q_{t}(1)\left(C-P_{t}^{D A}(1)\right)-\widehat{Q}_{t}(0)\left(C-\widehat{P}_{t}^{D A}(0)\right) \\
& =\left(Q_{t}(1)-\widehat{Q}_{t}(0)\right)\left(C-\widehat{P}_{t}^{D A}(0)\right)-Q_{t}(1)\left(P_{t}^{D A}(1)-\widehat{P}_{t}^{D A}(0)\right)
\end{aligned}
$$

where the first term represents the volume risk and the revenue loss due to a diminution of the consumption. The second term represents the price risk, which, in this case, becomes an opportunity to reduce the revenue losses of the retailer because the power 
sourcing in the spot market is less expensive than expected.

If we assume that the retailer has taken hedging positions at a volume $\Delta^{Q}$, then, noting $F$ the average price of the hedging contracts, its revenues losses, at time $t$ for scenario $i$, are

$$
\begin{aligned}
\bar{L}_{t}^{Q}= & -\widehat{Q}_{i t}(0)\left(C-\widehat{P}_{i t}^{D A}(0)\right)-\Delta^{Q}\left(\widehat{P}_{i t}^{D A}(0)-F\right) \\
& \quad+Q_{t}(1)\left(C-P_{t}^{D A}(1)\right)+\Delta^{Q}\left(P_{t}^{D A}(1)-F\right) \\
= & \left(Q_{t}(1)-\widehat{Q}_{i t}(0)\right)\left(C-\widehat{P}_{i t}^{D A}(0)\right)+\left(\Delta^{Q}-Q_{t}(1)\right)\left(P_{t}^{D A}(1)-\widehat{P}_{i t}^{D A}(0)\right) .
\end{aligned}
$$

The first term represents the revenues losses due to an unexpected consumption drop, whereas the second term represents the fact that the retailer has to sell the remaining volume $\left(\Delta^{Q}-Q_{t}(1)\right)$, bought at the price $F$, on the day-ahead market at the (lower) price $P_{t}^{D A}(1)$. If the retailer is risk averse, then the hedging volume was close to the expected consumption, i.e. $\Delta^{Q}=Q_{t}(1)$, and the second term is negative $\widehat{P}_{i t}(0) \geq$ $P_{t}(1)$. Therefore, contrary to the producers, the additional hedging term increases the revenues losses, due to the decrease in prices in the particular situation of the COVID-19 crisis.

Let $C=115.71 € / \mathrm{MWh}$ be the retail price in France $^{15}$, and $F=50.8 € / \mathrm{MWh}$ (source: European Energy Exchange) be the average price of future contracts late 2019 for year 2020. The total revenue impacts for retailers between March 16, 2020 to May 31, 2020, in absence of hedging (i.e. $\Delta^{Q}=0$ ), is -135 million $€$. However, assuming that retailers have taken hedging positions at the anticipated (business-asusual) consumption, then the total impacts amount to -1.1 billion $€$.

This finding explains why some retailers have reneged on ARENH contracts by arguing force majeure ${ }^{16}$ hence reshuffling market losses among market participants. ${ }^{17}$

\footnotetext{
${ }^{15}$ The retail price is evaluated considering the average retail price for households at $179.91 € / M W h$, source: https://www.statista.com/statistics/418087/ electricity-prices-for-households-in-france/, and the average industrial retail price at $81.15 € / M W h$, source: https://www.statista.com/statistics/595816/ electricity-industry-price-france/, and a ratio of $35 \%$ of total power consumption for households, source: http:www.cre.fr.

${ }^{16} \mathrm{https}$ ://www.reuters.com/article/us-edf-nuclearpower-idUSKBN2101B7.

${ }^{17}$ Whether the "force majeure" claim is legitimate is a matter for the law and thereby beyond the scope of this paper.
} 
Indeed, at the time ARENH contracts were signed (in December 2019), retailers' expectations about future spot prices and consumption from March onward could not incorporate the COVID-19 crisis. The full available volume of ARENH (100 TWh) were booked by retailers at the end of 2019 at the price of $42 € /$ MWh based on market expectations. During the lockdown, however, the power demand dropped considerably $(-11.5 \%)$ below the 2019 expectations and retailers had extra volumes they had to sell back on the spot market at an average price of $15 € /$ MWh. Given the hedging price $F=42 € / \mathrm{MWh}$ and the realized price of $15 € / \mathrm{MWh}$, and considering the ARENH volume $\Delta^{Q}$ to be $100 \mathrm{TWh} \times$ lock down duration $(11$ weeks $)=21.1 \mathrm{TWh}$, the ARENH contracts correspond to a financial issue of $571 \mathrm{M} €$ for retailers for the lockdown episode. This is around one half of the financial impacts evaluated above. As a matter of comparison, the net income of Total Direct Energie, one of the leading alternative retailer in France, was around $52 \mathrm{M} €$ in $2017 .^{18}$

Those results have shown that the crisis had enormous short-term consequences for market participants in the French electricity sector. In the next section, we draw a parallel between the observed market outcomes during the crisis and future outcomes that will prevail through the energy transition.

\section{Discussion}

The empirical results quantify how unprecedented demand reductions and low fuel prices, both caused by the crisis, have resulted in historically low electricity prices in France. In addition, containment measures have dramatically affected load patterns and thereby temporarily increased uncertainty around demand net of renewable production. The COVID-19 crisis is undoubtedly an extreme event, the negative impact of which was partially reduced for producers who had taken hedging positions in 2019, i.e. when the future prices did not reflect the realized spot prices. However, we claim that the observed market outcomes during the crisis are indicative of outcomes in a future with abundant renewable power, where spot and futures prices will fall in a more sustainable way. Unfortunately, those prices might be "too low" to guarantee grid

\footnotetext{
${ }^{18}$ https://total.direct-energie.com/fileadmin/Digital/Groupe/PDF/Rapport_annuels/ 2017/en/Annual_financial_report_2017.pdf.
} 
reliability by generating enough investments in absence of market design adjustments.

The market effects of the observed demand reductions (on average -11.5\%) is comparable to an equivalent increase of intermittent renewable power in the energy mix ( $+13 \%$ to reach the 2030 targets), assuming electricity demand remains stable through the energy transition because of energy efficiency improvements.

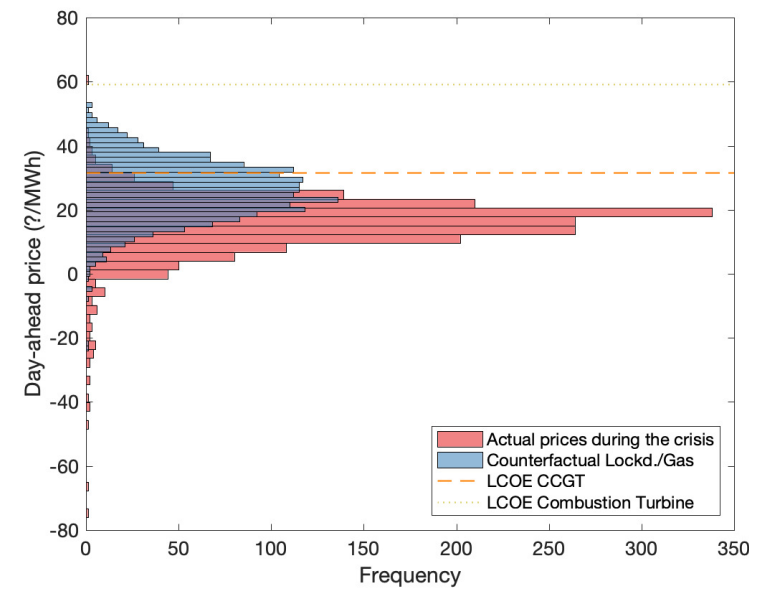

(a) Day-ahead prices

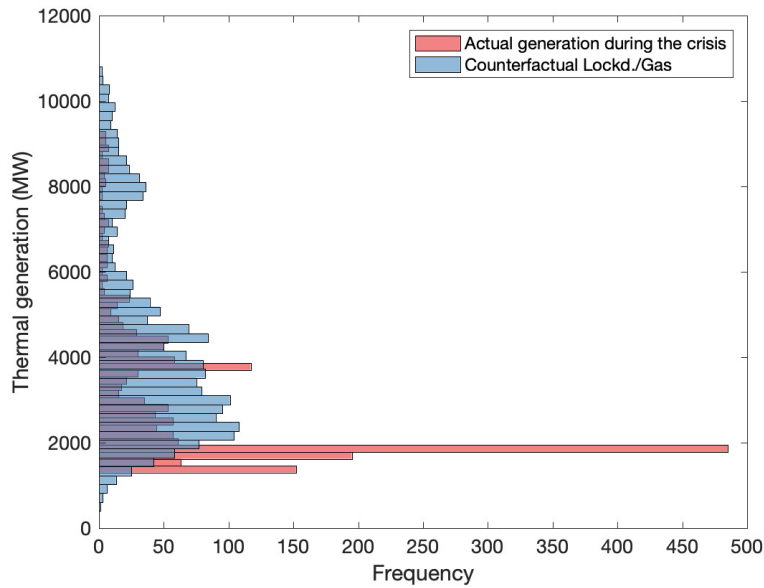

(b) Thermal generation

Figure 9: Histograms of actual and counterfactual outcomes

Figure 9a shows the distributions of energy prices observed during the crisis and their counterfactual values in scenario 3. This comparison reveals that the realized prices where lower and more volatile than usual, often taking values close to zero or even negative. We also plot the levelized cost of electricity (LCOE) for CCGT and combustion turbines entering service in 2025 as projected by EIA (2020). LCOE's are a measure of average costs by technology under assumptions about capacity factors, capital costs, and operations and maintenance costs. Realized prices are found almost always below the projected LCOE's. In addition, Figure 9b shows thermal generation during the crisis and its counterfactual values under business-as-usual conditions. The realized average output from thermal plants was $2.8 \mathrm{GW}$, implying a $14 \%$ capacity factor. This production level would only require $5.6 \mathrm{GW}$ of installed thermal capacity, nearly 4 times less than actual capacity in France, assuming this thermal energy mix 
to have a $50 \%$ capacity factor on average for the projected LCOE's to hold. ${ }^{19}$

Those results show that the energy transition would likely lead to many early retirements of thermal plants along with a dramatic reduction of new capacity investment in thermal capacity if: 1) there is no additional remuneration for flexibility and capacity availability, and 2) demand remain relatively stable at pre-crisis levels. Although informative about potential future outcomes, our results are not sufficient to conclude about the long-term consequences of such low prices and changing technological mix on system reliability.

Our literature review, however, demonstrates that achieving an efficient and reliable high-renewable system requires to address multiple externalities, and that the current European electricity market design is insufficient in that respect (Newbery et al., 2018). Some experts consider that externalities should be corrected by introducing additional "energy markets" with prices at finer spatial and time scales (Newbery et al., 2018; Leslie et al., 2020). Others emphasize the importance of capacity payments to address the externality related to capacity availability while keeping in mind market power issues and risk-aversion (Fabra, 2018; Petitet, Finon and Janssen, 2017). In particular, Fabra (2018) discusses reliability options, which provide capacity payments but also incentivize capacity availability and address market power issues. This solution has the advantage of avoiding the multiplicity of markets, which may lead to additional opportunities for abuse of market power and complications for market monitoring.

It is worth considering that there are capacity markets in several European countries, including France since 2017. However, those markets are still in a developing phase. We identify two main drawbacks. First, technologies are not discriminated according to their flexibility in the capacity auctions. Investments in flexible back-up generators, although required to balance short-term fluctuations of wind power production, are not incentivized differently than baseload power plants. Second, observed capacity prices have been highly volatile so far, ${ }^{20}$ and, as such, cannot yet provide a clear signal of long-term capacity needs.

The sanitary crisis is also a portent of more risky electricity markets. Investors'

\footnotetext{
${ }^{19}$ The projected LCOE's in EIA (2020) assume a $87 \%$ capacity factor for CCGT and 30\% for combustion turbines.

${ }^{20}$ For instance, capacity prices for year 2019 collapsed to zero in two out of six auctions.
} 
expectations about future market fundamentals and regulatory policies must account for the possibility of similar events causing large demand, or fuel price, variations over sustained periods of time, such as pandemics but also climate events. Future cash flows of long-term stranded assets, like power plants, are hence subject to increasing uncertainty. The introduction of more granular prices would result in even more volatile prices and time-varying cash flows. Conversely, capacity payments can contribute to mitigate revenue uncertainty, especially during extreme events.

\section{Conclusion}

The impacts of the COVID-19 crisis on the French electricity sector have been enormous. This paper has developed an empirical framework to quantify the effects of the crisis on demand, forecast errors, and market outcomes, accounting for cross-border trade with all adjacent countries. Our results document large demand reductions ($11.5 \%)$ and wholesale price drops $(-40 \%)$ leading to gross revenue losses for market participants at 1.2 billion $€(-45 \%)$, and net revenue losses for the distribution network operator at 100 million $€$. Retailers have borne the vast majority of the market losses, assuming all participants had forward contracts to cover their expected "precrisis" demand and supply volumes. Theses losses have been, however, redistributed in great majority to the historical producer, following the reneging of regulated supply contracts by retailers. ${ }^{21}$

More generally, the consequences of the crisis are evocative of the anticipated consequences of the ongoing energy transition: low energy prices and increased uncertainty caused by the large deployment of intermittent renewables. European electricity markets will experience similarly low and volatile prices along with decreasing market shares for fossil-fuel generators going through 2030. In the long-run, the energy transition may exacerbate reliability issues related the "missing money problem" and missing markets. We argue that capacity payments can be useful to guarantee capacity adequacy with-

\footnotetext{
${ }^{21}$ Moreover, an analysis over a longer time horizon would probably show different results. The pandemic has deeply affected the maintenance schedule of nuclear plants, leading to significant reduction of available nuclear capacity during winter. The spot prices will therefore be higher than usual. Retailers should hence be able to pocket the difference between the spot price and that of the regulated contracts.
} 
out introducing more granular energy prices, provided that they discriminate across technologies with respect to their contribution to system reliability, and offer stable long-term signals.

There are other important considerations not studied in this paper, in particular related to market power. Intermittent renewable plants will have larger shares in electricity auctions and will be marginal more frequently going through 2030. In theory, market power in electricity markets come from generators with positive probabilities to be marginal (Ausubel et al., 2014). Following Fabra and Llobet (2020), the energy transition will thus lead to a new competitive paradigm in electricity markets. We believe that empirical studies of strategic behaviors in European electricity markets during the crisis may provide important insights in that respect. 


\section{References}

AESO. 2020. "Impacts of the COVID-19 Pandemic and Low Oil Prices on Alberta's Power System." AESO. https://www.aeso.ca/assets/Uploads/ Pandemic-Low-Oil-Analysis-Summary-April-20-Final.pdf, accessed May 2020.

Alasseur, Clémence, and Olivier Féron. 2018. "Structural Price Model for Coupled Electricity Markets." Energy Economics, 75: 104-1199.

Ambec, Stefan, and Claude Crampes. 2012. "Electricity Provision with Intermittent Sources of Energy." Resource and Energy Economics, 34(3): 319-336.

Ausubel, Lawrence M, Peter Cramton, Marek Pycia, Marzena Rostek, and Marek Weretka. 2014. "Demand Reduction and Inefficiency in Multi-unit Auctions." The Review of Economic Studies, 81(4): 1366-1400.

Benatia, David. 2020a. "Electricity Markets under Lockdown: Insights from New York." Energy Forum.

Benatia, David. 2020b. "Reaching New Lows? The Pandemic's Consequences for Electricity Markets." USAEE Working Paper No. 20-454.

Benatia, David, and Étienne Billette de Villemeur. 2019. "Strategic Reneging in Sequential Imperfect Markets." Center for Research in Economics and Statistics Working Paper.

Borenstein, Severin, James B. Bushnell, and Frank A. Wolak. 2002. "Measuring Market Inefficiencies in California's Restructured Wholesale Electricity Market." American Economic Review, 92(5): 1376-1405.

Brown, David P., and Derek E.H. Olmstead. 2017. "Measuring Market Power and the Efficiency of Alberta's Restructured Electricity Market: An Energy-only Market Design." Canadian Journal of Economics/Revue Canadienne d'Économique, $50(3): 838-870$. 
Burlig, Fiona, Christopher Knittel, David Rapson, Mar Reguant, and Catherine Wolfram. 2019. "Machine Learning from Schools about Energy Efficiency." NBER Working paper.

Bushnell, James B., Erin T. Mansur, and Celeste Saravia. 2008. "Vertical Arrangements, Market Structure, and Competition: An Analysis of Restructured US Electricity Markets." American Economic Review, 98(1): 237-66.

Byers, Conleigh, Todd Levin, and Audun Botterud. 2018. "Capacity Market Design and Renewable Energy: Performance Incentives, Qualifying Capacity, and Demand Curves." The Electricity Journal, 31(1): 65-74.

Cicala, Steve. 2020. "Early Economic Impacts of COVID-19 in Europe: A View from the Grid." Tech. rep. Online, last accessed: May 6, 2020. University of Chicago.

Cramton, Peter, and Steven Stoft. 2006. "The Convergence of Market Designs for Adequate Generating Capacity."

CRE, Commission de Régulation de l'Énergie. 2020a. "Consommation Énergétique : les Effets du Confinement." Decryptages. https://www.cre.fr/Documents/Publications/Decryptages/ decryptages-n-63-consommation-energetique-les-effets-du-confinement.

CRE, Commission de Régulation de l'Énergie. 2020b. "Les Marchés de Détail de l'Électricité et du Gaz Naturel, 1er Trimestre 2020." https://www.cre.fr/Documents/Publications/Observatoire-des-marches/ observatoire-des-marches-de-detail-du-1e-trimestre-2020.

EIA. 2020. "Levelized Cost and Levelized Avoided Cost of New Generation Resources in the Annual Energy Outlook 2020." U.S. Energy Information Administration.

ERCOT. 2020. "COVID-19 Load Impact Analysis." ERCOT. http://www.ercot. com/content/wcm/lists/200201/ERCOT_COVID-19_Analysis_FINAL.pdf, accessed May 2020.

Fabra, Natalia. 2018. "A Primer on Capacity Mechanisms." Energy Economics, 75: 323-335. 
Fabra, Natalia, and Gerard Llobet. 2020. "Auctions with Unknown Capacities: Understanding Competition Among Renewables." CEPR Discussion Paper No. DP14060.

Fischer, Carolyn, and Richard G Newell. 2008. "Environmental and Technology Policies for Climate Mitigation." Journal of environmental economics and management, 55(2): 142-162.

Ghiani, Emilio, Marco Galici, Mario Mureddu, and Fabrizio Pilo. 2020. "Impact on Electricity Consumption and Market Pricing of Energy and Ancillary Services during Pandemic of COVID-19 in Italy." Energies, 13(13): 1-19.

Gillingham, Kenneth T, Christopher R Knittel, Jing Li, Marten Ovaere, and Mar Reguant. 2020. "The Short-run and Long-run Effects of Covid-19 on Energy and the Environment." Joule, 4(7): 1337-1341.

Graf, Christoph, Federico Quaglia, and Frank A Wolak. 2020. "Learning about Electricity Market Performance with a Large Share of Renewables from the COVID19 Lock-Down."

Henriot, Arthur, and Jean-Michel Glachant. 2013. "Melting-Pots and Salad Bowls: The Current Debate on Electricity Market Design for Integration of Intermittent RES." Utilities Policy, 27: 57-64.

Hogan, William. 2005. "On an "Energy only" Electricity Market Design for Resource Adequacy."

Joskow, Paul L. 2008. "Capacity Payments in Imperfect Electricity Markets: Need and Design." Utilities Policy, 16(3): 159 - 170. Capacity Mechanisms in Imperfect Electricity Markets.

Leach, Andrew, Nic Rivers, and Blake Shaffer. 2020. "Canadian Electricity Markets during the COVID-19 Pandemic: An Initial Assessment." Canadian Public Policy, 46(S2): S145-S159.

Leslie, Gordon, David I. Stern, Akshay Shanker, and Michael T. Hogan. 2020. "Designing Electricity Markets for High Penetrations of Zero or Low Marginal 
Cost Intermittent Energy Sources." USAEE Working Paper No.20-449, available at SSRN: https://ssrn.com/abstract=3601485.

Levin, Todd, and Audun Botterud. 2015. "Electricity market Design for Generator Revenue Sufficiency with Increased Variable Generation." Energy Policy, 87: 392406.

Mansur, Erin T. 2007. "Do Oligopolists Pollute Less? Evidence from a Restructured Electricity Market." The Journal of Industrial Economics, 55(4): 661-689.

Narajewski, Michał, and Florian Ziel. 2020. "Changes in electricity demand pattern in Europe due to COVID-19 shutdowns." Energy Forum.

Newbery, David, Michael G. Pollitt, Robert A. Ritz, and Wadim Strielkowski. 2018. "Market Design for a High-Renewables European Electricity System." Renewable and Sustainable Energy Reviews, 91: 695-707.

NYISO. 2020. "COVID-19 and the Electric Grid: Load Shifts as New Yorkers Respond to Crisis." NYISO. https://www.nyiso.com/-/ covid-19-and-the-electric-grid-load-shifts-as-new-yorkers-respond-to-crisis, accessed May 2020.

Percy, Steve, and Bruce Mountain. 2020. "Covid-19 and Social Distancing: Does It Show Up in the Demand for Electricity?" Energy Forum.

Petitet, Marie, Dominique Finon, and Tanguy Janssen. 2017. "Capacity Adequacy in Power Markets facing Energy Transition: A Comparison of Scarcity Pricing and Capacity Mechanism." Energy Policy, 103: 30-46.

PJM. 2020. "Estimated Impact of COVID-19." PJM. https://www.pjm. com/-/media/committees-groups/subcommittees/las/2020/20200505/ 20200505-item-03-covid-19-impact-update.ashx, accessed May 2020.

RTE. 2020. "L'Impact de la Crise Sanitaire sur le Fonctionnement du Système Électrique." Réseau Transport Électricité. https://www.rte-france.com/sites/ default/files/impacts_de_la_crise_sanitaire_covid-19_sur_le_systeme_ electrique.pdf, accessed May 2020. 
Ruan, Guangchun, Dongqi Wu, Xiangtian Zheng, S Sivaranjani, Haiwang Zhong, Chongqing Kang, Munther A Dahleh, and Le Xie. 2020. "A CrossDomain Approach to Analyzing the Short-run Impact of COVID-19 on the US Electricity Sector." JOULE-D-20-00678.

Wigand, F, R Brückmann, M Jimeno, F von Blücher, B Breitschopf, V Anatolitis, L Kitzing, M Dukan, P del Rio, O Fitch-Roy, et al. 2020. "Impact of COVID-19 on Renewable Energy Auctions."

Wolfram, Catherine D. 1999. "Measuring Duopoly power in the British Electricity Spot Market." American Economic Review, 89(4): 805-826.

Zhong, Haiwang, Zhenfei Tan, Yiliu He, Le Xie, and Chongqing Kang. 2020. "Implications of COVID-19 for the Electricity Industry: A Comprehensive Review." CSEE Journal of Power and Energy Systems, 6(3): 489-495. 


\section{Appendix}

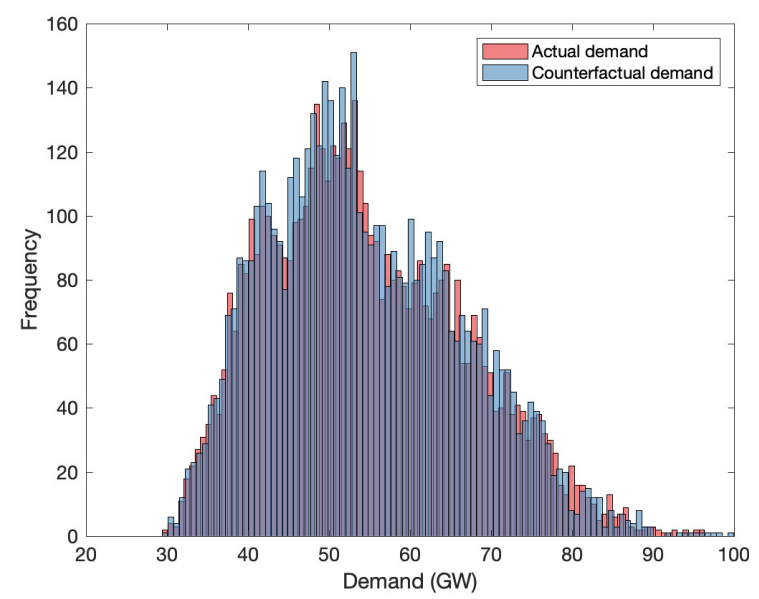

(a) Testing sample

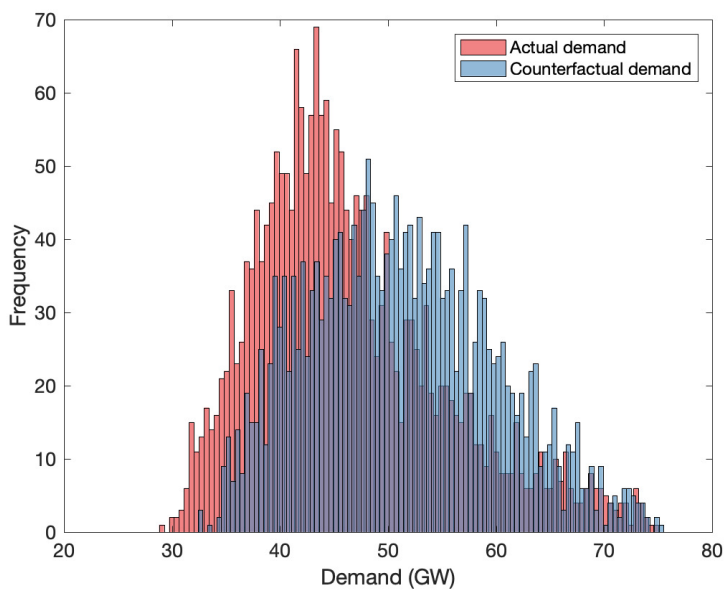

(b) March 1, 2020 to May 31, 2020

Figure 10: Histograms of actual load and FNet predictions

Table 13: Predictive performance (RMSPE)

\begin{tabular}{lccc}
\hline \hline & Thermal & Nuclear & Hydro \\
\hline Test set & 1.14 & 2.12 & 1.20 \\
$03 / 02-03 / 08$ & 0.86 & 1.97 & 1.63 \\
$03 / 09-03 / 15$ & 1.25 & 3.15 & 1.39 \\
$03 / 16-03 / 22$ & 1.93 & 6.38 & 1.54 \\
$03 / 23-03 / 29$ & 4.70 & 7.10 & 1.99 \\
$03 / 30-04 / 05$ & 3.27 & 4.46 & 1.95 \\
$04 / 06-04 / 12$ & 2.57 & 3.18 & 2.08 \\
$04 / 13-04 / 19$ & 2.20 & 3.49 & 1.91 \\
$04 / 20-04 / 26$ & 2.58 & 5.95 & 2.39 \\
$04 / 27-05 / 04$ & 1.40 & 3.49 & 1.66 \\
$05 / 05-05 / 10$ & 1.40 & 4.39 & 2.07 \\
$05 / 11-05 / 18$ & 1.47 & 4.50 & 1.95 \\
$05 / 19-05 / 24$ & 0.96 & 5.82 & 1.40 \\
$05 / 25-05 / 31$ & 0.77 & 4.97 & 1.43 \\
\hline
\end{tabular}

Notes: This table shows predictive performance of FNet for production by sector. 
Table 14: Changes in domestic production by sector (in GWh)

\begin{tabular}{lccc}
\hline \hline & Therm. & Nuclear & Hydro \\
\hline $03 / 16-03 / 22$ & -242.2 & -948.5 & -54.7 \\
$03 / 23-03 / 29$ & -710.5 & -1101.1 & -207.4 \\
$03 / 30-04 / 05$ & -467.4 & -422.5 & -14.9 \\
$04 / 06-04 / 12$ & -387.7 & -286.4 & -128.7 \\
$04 / 13-04 / 19$ & -302.9 & -376.7 & -150.2 \\
$04 / 20-04 / 26$ & -395.8 & -886.5 & -304.0 \\
$04 / 27-05 / 04$ & -185.6 & -472.8 & -128.9 \\
$05 / 05-05 / 10$ & -211.3 & -668.3 & 99.2 \\
$05 / 11-05 / 18$ & -188.6 & -661.3 & 195.6 \\
$05 / 19-05 / 24$ & 11.2 & -805.8 & 101.5 \\
$05 / 25-05 / 31$ & -1.1 & -763.3 & 126.6 \\
Std. errors & $(57.6)$ & $(115.2)$ & $(48.0)$ \\
\hline
\end{tabular}

Notes: This table shows changes in domestic production by sector, as predicted by FNet. Standard errors are robust to serial correlation within a day. 